\title{
A proteome-wide map of 20(S)-hydroxycholesterol interactors in cell membranes
}

\section{Yu-Shiuan Cheng}

California Institute of Technology

\section{Tianyi Zhang}

California Institute of Technology https://orcid.org/0000-0001-8289-3102

\section{Xiang Ma}

California Institute of Technology

\section{Sarida Pratuangtham}

California Institute of Technology

\section{Grace Zhang}

California Institute of Technology

\section{Alexander Ondrus}

Northern Alberta Institute of Technology

\section{Amirhossein Mafi}

California Institute of Technology

\section{Brett Lomenick}

California Institute of Technology

\section{Jeffrey Jones}

California Institute of Technology

Alison Ondrus ( $\nabla$ aondrus@caltech.edu )

California Institute of Technology https://orcid.org/0000-0002-6023-3290

\section{Article}

Keywords: Oxysterols, Live-cell Analysis, Chemoproteomics Probe, Osteogenic Molecules, Immune Response, Cancer

Posted Date: February 22nd, 2021

DOI: https://doi.org/10.21203/rs.3.rs-258030/v1

License: (9) This work is licensed under a Creative Commons Attribution 4.0 International License. Read Full License 
Version of Record: A version of this preprint was published at Nature Chemical Biology on November 19th, 2021. See the published version at https://doi.org/10.1038/s41589-021-00907-2. 


\title{
A proteome-wide map of 20(S)-hydroxycholesterol interactors in cell membranes
}

Yu-Shiuan Cheng, ${ }^{1}$ Tianyi Zhang, ${ }^{1}$ Xiang Ma, ${ }^{1}$ Sarida Pratuangtham, ${ }^{1}$ Grace C. Zhang, ${ }^{1}$ Alexander A. Ondrus, ${ }^{2}$ Amirhossein Mafi, ${ }^{1}$ Brett Lomenick, ${ }^{3}$ Jeffrey J. Jones, ${ }^{3}$ and Alison E. Ondrus ${ }^{1 *}$

${ }^{1}$ Department of Chemistry, Division of Chemistry \& Chemical Engineering, California Institute of Technology, Pasadena, California, 91125, United States

${ }^{2}$ Mathematics Department, Northern Alberta Institute of Technology, Edmonton, Alberta, T5G 2R1, Canada

${ }^{3}$ Proteome Exploration Laboratory, Beckman Institute, California Institute of Technology, Pasadena, California, 91125, United States

*Corresponding author email: aondrus@caltech.edu

\begin{abstract}
Oxysterols (OHCs) are hydroxylated cholesterol metabolites that play ubiquitous roles in health and disease. Due to the non-covalent nature of their interactions and unique partitioning in membranes, the analysis of live-cell, proteome-wide interactions of OHCs remains an unmet challenge. In this Resource, we present a structurally precise chemoproteomics probe for the osteogenic molecule 20(S)hydroxycholesterol $(20(S)-\mathrm{OHC})$ and provide a map of its proteome-wide targets in the membranes of living cells. Our target catalogue consolidates diverse $\mathrm{OHC}$ ontologies and demonstrates that $\mathrm{OHC}$ interacting proteins cluster with specific processes in immune response and cancer. Competition experiments reveal that $20(S)-\mathrm{OHC}$ is a chemo-, regio-, and stereoselective ligand for the protein Tmem97 ( $\sigma 2$ receptor), enabling molecular reconstruction of the Tmem97:20(S)-OHC binding site. Our results demonstrate that multiplexed, quantitative analysis of cellular target engagement can expose new dimensions of OHC activity and identify actionable targets for molecular therapy.
\end{abstract}

\section{Introduction}

Cholesterol is the most complex metabolite produced de novo by humans. ${ }^{1}$ It serves as a substrate for the biosynthesis of an ediface of signaling molecules, ${ }^{2}$ including steroid hormones, ${ }^{2}$ glucocorticoids, ${ }^{3}$ bile acids, ${ }^{4}$ and vitamin D. ${ }^{5}$ Over one hundred human enzymes are dedicated to modifying cholesterol structure, whereas no catabolic enzymes are available to derive energy from its breakdown. Instead, the human body expresses a multitude of receptors dedicated to cholesterol metabolites that control steroidogenesis, ${ }^{2}$ respiration, ${ }^{3}$ gut health, ${ }^{6}$ vision, ${ }^{7}$ and a repertoire of other essential processes. The gateway from cholesterol to all of these metabolites is a class of intermediates known as oxysterols (OHCs): specific mono-, di-, and polyhydroxylated cholesterol molecules that are barcoded by the configuration of 
their oxygen atoms. ${ }^{8}$ Although they serve as precursors to hundreds of metabolite structures, oxysterols are maintained at fleetingly low concentrations in the body, and are rapidly converted to more metabolically stable products. ${ }^{9}$ A growing body of evidence has revealed that these barcoded, ephemeral intermediates also function as sensitive, highly potent signaling molecules in critical processes such as neurotransmission, ${ }^{10}$ developmental signaling, ${ }^{11}$ and the innate immune response, ${ }^{12}$ where temporal control and specificity are paramount. Despite the fact that the chemical structures of OHCs directly inform their receptor preferences and biogenesis, only a fraction of the proteins that interact with these molecules is known. To tap into their signaling functions and trace the circuits that regulate their formation, chemoproteomic technologies to fingerprint the cellular targets of specific OHC structures are required.

An accurate portrait of proteome-wide $\mathrm{OHC}$ interactions in live cells requires that chemoproteomics probes preserve the oxygenation pattern of the natural congener as well as physiochemical properties for native membrane partitioning. ${ }^{13,14,15,16}$ In this work, we describe our design, synthesis, and application of a structurally precise photoaffinity probe for $20(S)$-hydroxycholesterol $(20(S)$ $\mathrm{OHC}$ ), an agonist of the developmental signaling protein Smoothened. ${ }^{17,18}$ Using this probe, we perform an unbiased analysis of live-cell 20(S)-OHC targets in the membrane proteome of mammalian cells. Our data reveals over 100 enriched 20(S)-OHC interactors that cluster into discrete molecular functions. We elucidate a set of protein interactors that competably engage 20(S)-OHC and show that the cancer biomarker protein Tmem97 is a regio-and stereoselective 20(S)-OHC target. Our work demonstrates the potential for chemoproteomic fingerprints to translate between the chemical structure of $\mathrm{OHC}$ signaling molecules and their biological functions.

\section{Design and synthesis of probe 1}

Chemoproteomics strategies for identifying cellular $\mathrm{OHC}$ interactions face a unique combination of challenges. In live cells, subtle features of chemical structure dictate the membrane environments that OHCs traverse and the targets to which they are exposed..$^{13,14,15,16,19}$ To capture the full complement of OHC interactions and the "fingerprint" of their cellular targets, chemoproteomics probes for cellular OHCs must preserve native membrane properties, retain oxygenation patterns recognized by specific receptors, and incorporate functionality to capture and identify live-cell targets. To address these requirements, we sought to modify natural $\mathrm{OHC}$ structures with a diazirine for live-cell photocrosslinking and an alkyne for downstream analysis. The diazirene functional group is benign to live cells, inert under ambient light, and can be photoactivated by $368 \mathrm{~nm}$ (long UV) light to generate a reactive carbene that covalently crosslinks protein residues within a single-digit angstrom radius. ${ }^{20,21,22}$ Diazirines in general are favored for their small size, bio-orthogonality, and low background labeling; for $\mathrm{OHC}$ probes in particular, this non-polar functional group can be introduced at a variety of positions without significantly influencing $\mathrm{OHC}$ 
membrane behavior. Alkynes likewise provide sterically minimal, biorthogonal modifications for "click"based appendage of crosslinked proteins to virtually any affinity tag (e.g. biotin), fluorescent reporter, or desired functionality. ${ }^{23}$ The complementary reactivities of diazirenes and alkynes underlie their emerging popularity as chemoproteomics handles and are especially suited to $\mathrm{OHC}$ probes.

We first chose to fashion a bifunctional probe for the OHC metabolite 20(S)-OHC. This molecule has been detected in the brain and placenta, ${ }^{24}$ and functions as a potent osteogenitor ${ }^{25}$ and teratogen. ${ }^{26}$ Significantly, in addition to binding other proteins, $20(S)-\mathrm{OHC}$ is a stereospecific ligand for the 7transmembrane receptor Smoothened (Smo), a gatekeeper in developmental Hedgehog signaling. ${ }^{17,18}$ Notably, the 20(R) epimer of this molecule is inactive at Smo. Stimulation of endogenous Smo activity by 20(S)-OHC and congeners can be assayed in NIH-3T3 cells, providing a platform for us to evaluate the biological activity of a $20(S)$-OHC probe relative to the parent molecule.

To enable an unbiased analysis of 20(S)-OHC targets in cells, we added functional handles that preserved the $\mathrm{C} 20(S)$-OHC pharmacophore, the $\alpha$ - and $\beta$-face topologies of the tetracyclic ring system, the accessible C3-hydroxyl group, and the length and hydrophobicity of the C17 side chain (Fig. 1a). Synthetically, we envisioned the use of an intramolecular $\mathrm{C}-\mathrm{H}$ activation for conversion of the $\mathrm{C} 19$ methyl group to an alkyne ${ }^{27}$ and a stereoselective Grignard addition to introduce a diazirine side chain to a $\mathrm{C} 17$ methyl ketone. ${ }^{28}$ In the forward sense, stereoselective hydrobromination of pregnenolone acetate ${ }^{29}$ and photoinduced C-H activation of the C19 methyl group in $\mathbf{3}^{27}$ provided ether $\mathbf{4}$ in $76 \%$ yield over two steps (Fig. 1b). Elaboration of the $\mathrm{C} 19$ primary alcohol to the alkyne via reductive elimination by elemental zinc in acetic acid, pyridinium chlorochromate oxidation to the $\mathrm{C} 19$ aldehyde, and homologation with the Seyferth-Glibert reagent ${ }^{30}$ provided the key intermediate 6. Gratifyingly, Grignard addition of 7 to 6 afforded exclusively the $20(S)$ alcohol $\mathbf{8}$, whereupon ketone deprotection and one-pot introduction of the C25 diazirine produced bifunctional photoaffinity probe $\mathbf{1}$ as an air- and ambient light-stable solid. In addition to furnishing $\mathbf{1}$, alkyne intermediate $\mathbf{6}$ represents a precursor to a library of bifunctional probes for side-chain oxysterols.

The structure of 1 was unambiguously established by 1D and 2D NMR spectroscopy. The presence of the diazirine was confirmed by a characteristic infrared $\mathrm{N}=\mathrm{N}$ stretching frequency at $1644 \mathrm{~cm}^{-1}$ and ultraviolet absorption at $353 \mathrm{~nm}$. Irradiation of 1 in organic solvent at $368 \mathrm{~nm}$ resulted in progressive extrusion of $\mathrm{N}_{2}$ with a half-life of 1.34 min (Fig. 1c). Probe 1 differs from the parent structure by only 4 atoms, $\sim 1.5 \AA$ in any dimension, and a $\log \mathrm{P}$ of 0.48 , and can be photoactivated to generate a reactive carbene for protein crosslinking.

To ensure that 1 preserves biological activity of $20(S)-O H C$, we assessed its ability to activate the 7-transmembrane protein Smoothened (Smo) in Shh-LIGHT2 cells, ${ }^{31}$ a mouse embryonic fibroblast line that bears a luminescent reporter of Smo-regulated Gli transcription (Fig. 1d). Commensurate with the 
known $(S)$ stereoselectivity of Smo:20-OHC binding, 20(S)-OHC induced reporter activity with an $\mathrm{EC}_{50}$ of $8.4 \mu \mathrm{M}$, whereas $20(R)-\mathrm{OHC}$ was inactive. Probe 1 induced Smo activity with an $\mathrm{EC}_{50}$ of $1.2 \mu \mathrm{M}$ and an enhanced magnitude of response, demonstrating that $\mathbf{1}$ retains activity at Smo. Differences in efficacy and magnitude of response may arise due to solubility and/or membrane properties introduced by the probe functionalities, underscoring the sensitivity of certain $\mathrm{OHC}$ activities to subtle changes in structure. To assess biochemical engagement between $\mathbf{1}$ and Smo, we photocrosslinked $\mathbf{1}$ to YFP-Smo expressed in HEK293T cells and isolated Smo protein using a GFP/YFP nanobody (Fig. 1e). Click ligation of a biotin handle and visualization of crosslinked protein revealed that Smo, but not overexpressed GFP, was efficiently labeled by $\mathbf{1}$. These studies established that $\mathbf{1}$ retains activity at a stereospecific $\mathrm{OHC}$ receptor and can selectively crosslink target proteins in live cells, supporting its utility as chemoproteomics probe to map live-cell 20(S)-OHC interactions.

\section{Establishment of OHC target labeling in live cells}

To quantitatively catalogue the protein fingerprint interaction of $20(S)-\mathrm{OHC}$ in live cells, we established conditions for live cell engagement, photochemical crosslinking, and biorthogonal tagging of target proteins (Fig. 2a). We performed these experiments in NIH-3T3 cells, which show an endogenous response to Smo activation and serve as a model to study osteogenesis ${ }^{32}$ and embryogenesis. ${ }^{33}$ For live cell engagement, we used an incubation time of $30 \mathrm{~min}$ to minimize effects of $\mathrm{OHC}$-induced protein expression or degradation. $^{34,35}$ To photocrosslink target proteins, we removed unbound probe and irradiated cells on ice at $368 \mathrm{~nm}$ for $5 \mathrm{~min}$. To label crosslinked proteins, we lysed cells and performed a click reaction to ligate a TAMRA fluorophore to the alkyne handle in $\mathbf{1}$.

SDS page analysis of labeled proteins revealed a discrete set of bands that appeared in a probe-, UV-, and copper-dependent manner, indicating that they represented 1-crosslinked target proteins (Fig. 2b). Cell fractionation revealed that the majority of labeled proteins, including prominent bands at approximately $13 \mathrm{kDa}, 21 \mathrm{kDa}$, and $37 \mathrm{kDa}$, appeared exclusively in the membrane fraction (Fig. 2c). To focus on these enriched targets and identify novel 20(S)-OHC interactors in the membrane proteome, we employed this fractionation method for remainder of our experiments. Analysis of the membrane proteome demonstrated these bands were labeled in a manner that showed good signal-to-background at $1 \mu \mathrm{M}$ (Fig. $2 \mathrm{~d}$ ). Competition with unlabeled $20(S)-\mathrm{OHC}$ revealed that the $21 \mathrm{kDa}$ band was competable in a dosedependent manner, showing $85 \%$ reduction in signal at a competitor concentration of $50 \mu \mathrm{M}$ (Fig. 2e). The

ability to label membrane proteins in a probe, UV, and click catalyst-dependent fashion and to identify proteins dose-dependently competed by 20(S)-OHC established the utility of $\mathbf{1}$ as a live cell chemoproteomics probe. 


\section{Analysis of enriched OHC targets}

To profile the entire complement of 1 labeling in the membrane proteome, we replaced the TAMRA azide in the click reaction with a biotin azide to label crosslinked proteins. A survey of biotin azide reagents revealed superior labeling with a copper-chelating biotin picolyl azide, ${ }^{36}$ which we therefore used in subsequent analysis. To isolate crosslinked proteins using streptavidin enrichment, we removed excess biotin through acetone precipitation, resolubilized the membrane proteome in SDS/Igepal buffer, and isolated biotinylated proteins on streptavidin agarose beads (Fig. 3a). SDS-PAGE and Western blot analysis using streptavidin-conjugated IR dye revealed that bands at 13, 21, and $37 \mathrm{kDa}$ were effectively isolated using this protocol, whereas Smo was inefficiently solubilized in SDS/Igepal detergent (Fig. S1). For global target profiling, we used this protocol in the presence and absence of $1 \mu \mathrm{M} 1$ at a normalized concentration of $0.01 \%$ DMSO. On-bead digestion of streptavidin-enriched proteins and tandem isotope labeling of replicate samples enabled multiplexed real-time search-enabled MS3-based mass spectrometry analysis (RTS-SPS-MS $)^{37}$ of $\mathbf{1}$ interactors in the membrane proteome.

Our results revealed 12 proteins that were enriched by 25-fold relative to DMSO alone, and 106 proteins enriched by 5 - to 25 -fold at a p-value of $<0.002$ (Fig. 3b). Comparison with transcript levels from RNA-seq analysis ${ }^{38}$ revealed no significant correlation between target protein enrichment and expression, indicating that enhancement was not solely a reflection of abundance (Fig. S2c). The most enriched set consisted of proteins biochemically established to bind OHCs ( $\mathrm{NPC1}^{39,40}$ and $\mathrm{Cav}^{41}$ ), cholesterol-binding proteins $\left(\operatorname{Vdac}^{42,43}\right)$, and proteins directly involved in cholesterol homeostasis $\left(\mathrm{Tmem} 97^{44}\right)$. The set also included metabolic proteins that act on sterol substrates (Ldah, ${ }^{45} \mathrm{Ephx} 1^{46,47}$ ) or participate in redox complexes associated with cholesterol biosynthesis (Vkorc111). ${ }^{48}$ Three of the proteins (Nptn, Bsg ${ }^{49,50}$ Endod $1^{51}$ ) function as adaptors that control trafficking and activity of protein complexes in specialized membranes. Performing our affinity enrichment protocol using label-free instead of TMT analysis revealed a nearly identical target profile with respect to identity and enrichment, demonstrating that the method of quantification did not significantly influence the target set (Fig. S2a,b).

A key aspect of $\mathrm{OHC}$ function involves their unique effect on membrane proteins sensitive to cholesterol content. ${ }^{52}$ Protein-protein interactions, membrane shape and curvature, and various processes in internalization, secretion, and vesicular trafficking are sensitive to infiltration of OHCs that disrupt cholesterol-rich environments and increase the fluidity of local membranes. ${ }^{13,14,15,16}$ Recent studies have demonstrated that signal transduction by GPCRs, cytokine receptors, and ion channels are especially sensitive to disruptive $\mathrm{OHC}$ interactions. ${ }^{53}$ Accordingly, network analysis of $\mathrm{OHC}$ targets can reveal interactions, membrane topologies, and cellular circuits that are responsive to OHCs. To identify cellular locations, processes, and diseases associated with the $\mathbf{1}$ interaction fingerprint, we performed Gene Set Enrichment Analysis (GSEA) using 1-enriched proteins. ${ }^{54}$ Analysis using the Gene Ontology (GO) gene 
set revealed a top list of $15 \mathrm{GO}$ terms for cellular components, molecular functions, and biological processes with an FDR of $<0.1$ (Fig. 3c). As a testament to the stringency of our fractionation protocol, membrane organelles and subcompartments dominated the cellular component terms for 1-binding proteins. Among the most highly enriched membrane components were the Golgi apparatus and plasma membrane-ER membrane networks, consistent with the observed localization of 20(S)-OHC to the Golgi and perinuclear regions, ${ }^{55}$ and in contrast to the predominant plasma membrane localization of cholesterol itself. ${ }^{56,5758}$ Likewise, protein interactors of $\mathbf{1}$ were associated with GO molecular functions that involved molecular signal transduction and transport across the membrane. The most highly represented GO biological processes included membrane lipid metabolism and sphingolipid metabolism in particular, in line with the observation that $\mathrm{OHCs}$ posttranslationally enhance the activity of enzymes involved in sphingomyelin biosynthesis. $^{59}$

To identify associations between 1-binding proteins and processes in human health and disease, we performed GSEA using the immunologic and oncogenic signature gene sets (Fig. 3d,e). The immunologic gene set with the highest representation of 1-enriched targets was GSE23505_IL6_IL1_VS_IL6_IL1_IL23_TREATED_CD4_TCELL_DN (NES $=2.92$, FDR $=0.009)$. This gene set is downregulated in ROR $\gamma$-dependent, TGF $\beta$-independent initiation of CD4+T cell differentiation into Th17 helper cells. ${ }^{60}$ Overlapping sets of signature genes and 1-enriched proteins raises the possibility that OHCs may directly intervene in this mechanism of immune cell differentiation and associated autoimmune disease. The oncogenic gene set containing the most 1-enriched targets was TBK1.DF_UP $(N E S=2.14$, FDR $=0.071)$, a set of genes upregulated by the kinase TANK binding kinase 1 in KRAS-mutant lung adenocarcinoma cells. ${ }^{61}$ Since targeting of TBK1 in KRAS mutant cancer cells is synthetically lethal, inhibition of OHC-coordinated processes in these cells may represent an avenue for the treatment of refractory KRAS mutant cancers. The identification of specific processes in immune system function and cancer signaling networks that integrate OHCs highlights new opportunities for drug design and therapeutic targeting.

\section{Identification of enriched and competable OHC targets}

Cellular OHCs interact with both high- and low-affinity targets to effect their biological functions. In live cells, competability can arise due to structure-specific ligand displacement, differential binding kinetics, or cell-specific phenomena such as receptor populations and local concentrations. We next sought to determine which live-cell OHC interacting proteins could be out-competed by unlabeled 20(S)-OHC. To optimize the competability of $20(S)$-OHC interactions, we focused on conditions that reduced non-specific labeling and enhanced sensitivity to competition. Co-application of $0.5 \mathrm{mM} \mathrm{M \beta CD}$ with $1 \mu \mathrm{M} 1$ in the presence or absence of $50 \mu \mathrm{M} 20(S)$-OHC competitor reproducibly solubilized all sterols and provided 
robust competition of the $21 \mathrm{kDa}$ band identified by in-gel analysis (Fig. 2e). Because M $\beta C D$ can perturb cellular cholesterol content, we identified an MBCD concentration that preserved equal intensities of noncompetable bands in the presence and absence of competitor (Fig. S3a). ${ }^{62}$

Our competition experiments included three conditions, namely $1 \mu \mathrm{M} 1$ alone, $1 \mu \mathrm{M} 1+50 \mu \mathrm{M}$ 20(S)-OHC competitor, and vehicle alone at a constant concentration of $0.5 \mathrm{mM} \mathrm{M} \beta \mathrm{CD}$ and $0.01 \%$ DMSO. Triplicate experiments for each condition entailed live cell incubation, photoinduced target crosslinking, lysis, membrane isolation, and click-based tagging of crosslinked proteins with biotin (Fig. 4a). Streptavidin enrichment, on-bead digestion, and unique labeling with isobaric peptide tags enabled multiplex RTS-SPS-MS ${ }^{3}$ analysis to identify targets that were both enriched relative to DMSO and competable by $20(S)-\mathrm{OHC}$.

Our analysis revealed 12 proteins that were enriched by 1 by more than 7-fold at a p-value of 0.05 (Fig. 4b). Comparison of our enriched targets in the presence and absence of M $\beta C D$ demonstrated that, while $\mathrm{M} \beta C D$ reduced the magnitude of fold changes versus DMSO, neither the identity nor the relative enrichment of probe targets were significantly altered (Fig. $4 b$ and Fig. S3b,c). We again observed the proteins Tmem97, Ephx1, Cav1, Vkorc111, Ldah, Vdac2, and Bsg in the top 5\% of target enrichment, comprising $\sim 60 \%$ of the most enriched proteins in our previous experiments (Fig. 3b). Another 89 targets were enriched at between 2.75 and 7 -fold at a p-value of 0.05 , representing a selection of transmembrane proteins, signal transduction proteins, lipid biosynthetic enzymes, and membrane trafficking/adaptor proteins identified in our previous GO analysis. Enriched proteins in these experiments also involved in Golgi membrane homeostasis (Tmem199 $9^{63,64}$ ), transmembrane proteins of unannotated function (Tmem238, Smim4), and the caveolin isoform Cav2.

As anticipated, only a subset of 1 interactions were competable by $20(S)-O H C$ (Fig. 4d,e). In this dataset, a sharp divide separated the top $0.3 \%$ of proteins from less competable interactors. The most competable proteins encompassed the highly enriched targets Tmem97, Ephx1, and Cav1. In addition, the list included Abcb1 (P-glycoprotein 1), an ATP-dependent multidrug transporter that can translocate sterol metabolites across the membrane, ${ }^{65,66}$ and Arxes 1/2, a retrotransposed protease gene on the X-chromosome that plays a role in adipogenesis. ${ }^{67}$ Both Abcb1b and Arxes $1 / 2$ also appear with in the top $2 \%$ of proteins enriched by 1 .

The full fingerprint of direct $\mathrm{OHC}$ binding proteins provided us with an opportunity to probe the engagement of OHCs and proteins with relevant biological functions. We selected a collection of targets with a range of competabilities to query the correlation between our MS results and immunodetected endogenous protein, and to highlight potential roles for direct $\mathrm{OHC}$ targets in cellular signaling networks (Fig. 4f). Briefly, live cell crosslinking of 1 in the presence or absence of 20(S)-OHC, biotinylation of crosslinked proteins, streptavidin enrichment, and Western blot detection with specific antibodies provided 
an orthogonal measure of target engagement in cells. A highly competable protein identified in our data was Gas1, an upstream Smo regulator that coordinates the Hedgehog signaling pathway in embryonic development. ${ }^{68,69}$ Competable binding of Gas1 by 20(S)-OHC complements recent findings that Gas1 localizes to cholesterol microdomains as an obligate part of its activity in Hh signaling, ${ }^{70}$ and suggests that endogenous OHCs may directly or indirectly contribute to this mechanism of regulation. Moderately competable proteins that consistently appeared in our enrichment data were the Vdac isoforms 1 and 2. Vdac isoforms are known to play a direct role in steroidogenesis by regulating the transport of cholesterol from the outer mitochondrial membrane to the inner mitochondrial membrane for conversion to pregnenolone by Cyp11a1. ${ }^{71,72}$ The direct binding to $\mathbf{1}$ to Vdac provides a mechanism by which OHCs might act as a biochemical rheostat for steroidogenesis. To query less competable targets, we likewise verified engagement of the scaffolding protein Reep5, which plays a structural role in the architecture of sarcolemmal membranes in muscle cells, ${ }^{73}$ the protein Gpr107, which chaperones receptors to organelle membranes, ${ }^{74}$ and the adaptor protein Tmem199, an assembly factor in vacuolar ATPase complexes that control energy-dependent acidification of cellular organelles. ${ }^{63,64}$ In each of these cases, $\mathbf{1}$ pulled down endogenous protein to an extent that correlated with proteomic abundance, verifying that our proteomewide profiling can provide a quantitative catalogue of 1-interacting proteins in living cells (Fig. S4a,b).

\section{Discovery of Tmem97 as a selective OHC target}

The most enriched and competable protein identified in our studies was Tmem97, a transmembrane protein with a molecular weight of $21 \mathrm{kDa}$ - approximately the same molecular weight as the competable band identified in our in gel fluorescence analysis (Fig. 2e). Tmem97, also known as the $\sigma 2$ receptor, is a protein biomarker that is overexpressed in proliferative tumors, and is a target for PET imaging in the clinic. ${ }^{75}$ Originally characterized by its pharmacological profile, Tmem97 has also been investigated as a non-opioid target for psychiatric conditions and neuropathic pain. ${ }^{44}$ Identification of the Tmem 97 gene in $2017^{76}$ and genetic perturbation studies subsequently established an integral role for Tmem 97 in cholesterol homeostasis, where it regulates trafficking of the cholesterol transporter NPC1 from the ER to the lysosome. ${ }^{77,78}$ For its utility as a cancer radioimaging agent and potential relevance to lysosomal cholesterol storage diseases, Tmem97 is a valuable therapeutic target. ${ }^{79}$ However, no endogenous ligand for Tmem97 has been established, and no structural data is available to guide pharmacological design.

To determine whether Tmem97 represented the $21 \mathrm{kDa}$ band identified in our gel-based assays, we took advantage of ligands selective for Tmem97 or the structurally unrelated $\sigma 1$ receptor. Using the $\sigma 1$ ligand PRE- $084^{80}$ or the Tmem97 ligand BIMU- $8^{81}$ as competitors, live-cell crosslinking to 1, TAMRA labeling, and SDS-PAGE analysis revealed that the Tmem97 ligand, but not the $\sigma 1$ receptor ligand, effectively out-competed labeling by $\mathbf{1}$ (Fig. 5a). Biotin labeling and streptavidin pulldown confirmed that 
the $21 \mathrm{kDa}$ band labeled was isolated only in the presence of the $\sigma 1$ receptor ligand, whereas competition by the Tmem97 ligand prevented crosslinking, subsequent tagging, and isolation. Both Western blot imaging of biotin-tagged protein and immunodetection supported the identity of the $21 \mathrm{kDa}$ band as Tmem97. In addition, competition of 1 crosslinking by 20(S)-OHC, biotin/streptavidin enrichment, and immunodetection of isolated protein with a Tmem97 antibody showed that inhibition of Tmem97 signal was commensurate with competition of the $21 \mathrm{kDa}$ band in TAMRA fluorescence analysis (Fig. 5b).

Finally, to verify that the $21 \mathrm{kDa}$ band labeled by 1 was indeed Tmem97, we used CRISPR/Cas9 to ablate expression of Tmem97 in a population of NIH-3T3 cells (Fig. 5c). Photoaffinity crosslinking of $\mathbf{1}$ in wild-type and Tmem97-knockout cells demonstrated that loss of Tmem97 eliminated the prominent band at $21 \mathrm{kDa}$, as determined by SDS-PAGE analysis of the TAMRA-labeled membrane proteome and isolation of crosslinked protein from each cell population.

Because lipid-based ligands interact with receptors on layers of competability, we sought to determine ability of structurally diverse molecule to out-compete labeling by $\mathbf{1}$. Neither the long-chain lipid palmitoylethanolamide (PEA) nor the polyhydroxylated carbocycle inositol could effectively reduce labeling by $\mathbf{1}$, indicating that neither bound to Tmem 97 at the same site as $\mathbf{1}$ and 20(S)-OHC (Fig. 5d). To determine whether Tmem97:1 binding could distinguish hydroxylation patterns within the sterol structure, we evaluated competition by unmodified cholesterol or the regioisomeric oxysterol 25-OHC. While cholesterol itself was a poor competitor of $\mathbf{1}, 25-\mathrm{OHC}$ could partially outcompete labeling by $\mathbf{1}$, indicating that Tmem97 is sensitive to the extent and pattern of sterol hydroxylation. Finally, we tested whether the configuration of the $\mathrm{C} 20$ alcohol could differentiate competition by $20(S)$ - and 20(R)-OHC. Notably, the $20(S)$ stereochemistry is produced endogenously by Cyp11a1 oxidation of cholesterol en route to pregnenolone. $^{82}$ Competition with either the $\mathrm{C} 20(S)$ or the $\mathrm{C} 20(R)$ epimer revealed that $20(R)$-OHC competed only $75 \%$ of probe labeling at a concentration of $50 \mu \mathrm{M}$, whereas competition by $50 \mu \mathrm{M} 20(S)$ OHC completely abolished labeling, indicating a stereochemical preference for a $\mathrm{C} 20(S)-\mathrm{OH}$ interaction.

Tmem97 is phylogenetically related to the enzyme 3 - $\beta$-hydroxysteroid- $\Delta^{8}, \Delta^{7}$-isomerase (Emopamil-binding protein, Ebp), which catalyzes migration of the C8-C9 double bond in zymosterol/zymostenol to its C7-C8 position in lathosterol/dehydrolathosterol. ${ }^{83,84}$ Despite their evolutionary relationship, Tmem97 lacks an acidic residue homologous to E122 in Ebp (human numbering), which is required for enzyme catalysis. ${ }^{85}$ To determine a binding site for 20(S)-OHC within Tmem97, we used the recently solved cryo-EM structure of human Ebp (hEbp, PDB 6OHT) ${ }^{86}$ as a template to predict the structure of mouse Tmem97 (82\% pairwise identity with human Tmem97) using the Robetta server. ${ }^{87}$ We embedded the resulting model within a POPC membrane and performed all-atom molecular dynamics simulations to equilibrate the membrane-bound Tmem97 structure. Docking of 20(S)-OHC into this model produced a stable pose in which the $20(S)$-OHC binding site shares several homologous residues with the 
active site in hEpb (Fig. 5e). As in Ebp and other sterol-binding proteins, an array of hydrophobic and aromatic residues line a central binding cavity with a helical "cap" at the top. The C3 hydroxyl group of 20(S)-OHC forms a hydrogen bond to the imidazole side chain of H106, while the isooctyl tail is accommodated by a hydrophobic pocket composed of W12, L16, F88, V146, and Y150. Hydrophobic interactions between the isooctyl side chain and these residues would disfavor introduction of a polar group at $\mathrm{C} 25$, providing a rationale for reduced competition of $\mathbf{1}$ by $25-\mathrm{OHC}$ vs $20(S)-\mathrm{OHC}$. Interestingly, the Y150 phenolic oxygen is located within $6.7 \AA$ of the $\mathrm{C} 20$ alcohol, but no hydrogen bond is apparent in this structure.

To ascertain whether residues in the proposed binding pocket influenced the extent of Tmem97 labeling by 1 or degree of competition with 20(S)-OHC, we transiently overexpressed FLAG-tagged Tmem97 and constructs containing mutations at residues that interact with 20(S)-OHC in our model (Fig. 5f). While the F88A mutant protein was not expressed, the Y150A, E61A, and W95A mutants were robustly produced, appearing $\sim 3 \mathrm{kDa}$ higher in apparent MW than endogenous Tmem97 due to the presence of the FLAG epitope. Strikingly, while the E61A and W95A mutants were labeled by 1 and competable with 20(S)-OHC to the same extent as the wild-type protein, the Y150A mutant was not labeled. As no distinct interactions favor binding to the $(S)$ over the $(R)$ 20-OHC epimer, we hypothesize that selective competition by the $20(S)$ epimer of 20-OHC may be a result of conformational and/or dynamic factors that govern Tmem97-20(S)-OHC binding in the cell membrane. Our identification of Tmem97 as a highly enriched, stereoseletively competable target of 20(S)-OHC raises an intriguing possibility for an endogenous role of $\mathrm{OHC}$ metabolites in Tmem97-regulated cholesterol homeostasis. Our model offers a structural template for the rational design of Tmem97 inhibitors as therapeutics of lysosomal cholesterol storage diseases and as radioligands for cancer diagnosis.

\section{Discussion}

While cholesterol is the most abundant lipid present in mammalian cell membranes, OHCs are transient species that exist at low concentrations in cells. ${ }^{9}$ Additional hydroxylation of OHCs relative to cholesterol confers these molecules with privileged access to cholesterol binding sites and membrane environments, where their presence can profoundly disrupt locales and resident proteins. The activity of OHCs in cells is a function of their affinity for specific receptors and their constellation of cellular targets. Well-known for their signaling roles, the complete set of OHC binding remain virtually unknown, and therapeutic opportunities associated with their direct targets and functions are largely untapped.

In this work, we describe our design, synthesis, and application of a chemoproteomics OHC probe to fingerprint $\mathrm{OHC}$ interactions in live mammalian cells. By incorporating structurally benign functional groups within the signaling molecule $20(S)-\mathrm{OHC}$, we establish a probe that precisely mimics the natural 
molecule and preserves its signaling activity in cells. We create a reproducible, quantitative protocol for competing targets of $\mathbf{1}$ in the native environments and perform multiplexed, proteome-wide analysis. We reveal $\mathrm{OHC}$ targets on a spectrum of competability that have functional roles in signal transduction, protein trafficking, and membrane lipid metabolism, and we identify specific processes in immune response and cancer that are functionally integrated with $\mathrm{OHC}$ target proteins. We demonstrate that the metabolic regulator protein Tmem97 is a stereo- and regioselective target of OHCs in live cells, illuminating its potential roles in metabolism and cancer, and providing a template to design molecules that intervene in its functions.

We note that the membrane proteome examined in this study excludes nuclear hormone receptors that bind $\mathrm{OHCs}$; we are currently profiling the nuclear fraction to quantify OHC engagement with known targets and yet-unidentified $\mathrm{OHC}$ receptors. In the future, chemoproteomics analysis of sterol and other lipid and hydrophobic metabolites will benefit from new reagents for small molecule delivery to cells, such as synthetic LDL particles ${ }^{88}$ and next-generation cavitands. ${ }^{89}$ Improved methods for membrane protein solubilization, combined with powerful advances in liquid chromatography/mass spectrometry of hydrophobic peptides, can likewise enhance the resolution and detection of target proteins. ${ }^{90}$ Critically, enhanced coverage hinges on fundamental improvements in diazirine photocrosslinking chemistry ${ }^{91}$ and continued optimization of click labeling protocols. ${ }^{23}$ Moving forward, the multiplexing capability of this method can be readily extended to an array of probe and competitor structures, providing a platform to distinguish targets of metabolite families. In synergy with appropriate data analysis, chemoproteomic profiling can inform target prediction and aid the design of metabolite-inspired drugs. More broadly, the identification of metabolite targets in cells can integrate chemical structure and biological activity, providing new dimensions to our understanding of human health.

\section{Author contributions}

Y-S.C. performed all gel- and mass spectrometry-based chemoproteomics experiments, mass spectrometry data processing, cloning, and gene editing. T.Z., X.M., Y-S.C., and G.C.Z. performed chemical synthesis. S.P. performed homology modeling and molecular docking experiments. G.C.Z. performed ShhLIGHT2 signaling assays. A.A.O. performed mass spectrometry data analysis and visualization. A.M. performed molecular dynamics simulations. B.L. participated in experimental design, provided new reagents/analytical tools, and participated in data analysis. J.J.J. participated in data analysis. A.E.O., YS.C., T.Z., and S.P. wrote the manuscript.

\section{Acknowledgements}


The authors thank A. Li for synthesizing 20(R)-OHC intermediates, Beckman Institute/Caltech Flow Cytometry Cell Sorting Facility for cell sorting, and A.K. Menon and F.R. Maxfield for helpful discussions . This work was funded by the Margaret Early Foundation Research Trust, a John Stauffer Charitable Trust SURF Fellowship to T.Z., a William N. Lacy SURF fellowship to S.P., and NIH training grant NIH GM07616 to G.C.Z. The Proteome Exploration Laboratory was supported by NIH OD010788, NIH OD020013, the Betty and Gordon Moore Foundation through grant GBMF775 and the Beckman Institute at Caltech.

\section{References}

${ }^{1}$ Maxfield, F. R. \& van Meer, G. Cholesterol, the central lipid of mammalian cells. Curr Opin Cell Biol 22, 422-429 (2010).

2 Miller, W. L. \& Auchus, R. J. The molecular biology, biochemistry, and physiology of human steroidogenesis and its disorders. Endocrine Rev 32, 81-151 (2011).

${ }^{3}$ Arlt, W. \& Stewart, P. M. Adrenal corticosteroid biosynthesis, metabolism, and action. Endocrin Metab Clin 34, 293-313 (2005).

${ }^{4}$ Lefebvre, P., Cariou, B., Lien, F., Kuipers, F. \& Staels, B. Role of bile acids and bile acid receptors in metabolic regulation. Physiol Rev 89, 147-191 (2009).

5 Jones, G., Strugnell S. A. \& DeLuca, H. F. Current understanding of the molecular actions of Vitamin D. Physiol Rev 78, 1193-1231 (1998).

${ }^{6}$ Gérard, P. Metabolism of cholesterol and bile acids by the gut microbiota. Pathogens 3, 14-24 (2013).

${ }^{7}$ Javitt, N. B. \& Javitt, J. C. The retinal oxysterol pathway: A unifying hypothesis for the cause of agerelated macular degeneration. Curr Opin Ophthalmol 20, 151-157 (2009).

${ }^{8}$ Schroepfer, G. J. Oxysterols: Modulators of cholesterol metabolism and other processes. Physiol Rev 80, 361-554 (2000).

${ }^{9}$ Griffiths, W. J. \& Wang, Y. Analysis of oxysterol metabolomes. Biochimica Et Biophysica Acta BBA Mol Cell Biol Lipid 1811, 784-799 (2011).

${ }^{10}$ Paul, S. M. et al. The major brain cholesterol metabolite 24(S)-hydroxycholesterol is a potent allosteric modulator of N-methyl-D-aspartate receptors. J Neurosci 33, 17290-17300 (2013).

${ }^{11}$ Dwyer, J. R. et al. Oxysterols are novel activators of the Hedgehog signaling pathway in pluripotent mesenchymal cells. J Biol Chem 282, 8959-8968 (2007).

${ }^{12}$ Spann, N.J., \& Glass, C.K. Sterols and oxysterols in immune cell function. Nat Immunol 14, 893-900 (2013). 
${ }^{13}$ Massey, J. B. \& Pownall, H. J. Structures of biologically active oxysterols determine their differential effects on phospholipid membranes. Biochemistry 45, 10747-10758 (2006).

14 Bielska, A. A. et al. Side-chain oxysterols modulate cholesterol accessibility through membrane remodeling. Biochemistry 53, 3042-3051 (2014).

${ }^{15}$ Olkkonen, V. M. \& Hynynen, R. Interactions of oxysterols with membranes and proteins. Mol Aspects Med 30, 123-133 (2009).

${ }^{16}$ Massey, J. B. Membrane and protein interactions of oxysterols. Curr Opin Lipidol 17, 296-301 (2006).

${ }^{17}$ Nachtergaele, S. et al. Oxysterols are allosteric activators of the oncoprotein Smoothened. Nat Chem Biol 8, 211-220 (2012).

${ }^{18}$ Nedelcu, D., Liu, J., Xu, Y., Jao, C. \& Salic, A. Oxysterol binding to the extracellular domain of Smoothened in Hedgehog signaling. Nat Chem Biol 9, 557-564 (2013).

${ }^{19}$ Maxfield, F. R. \& Menon, A. K. Intracellular sterol transport and distribution. Curr Opin Cell Biol 18, 379-385 (2006).

${ }^{20}$ Winnewisser, M., Möller, K. \& Gambi, A. Chemistry of diazirines. in Chemistry of Diazirines (ed. Liu, M. T. H.) vol. 1 19-55 (CRC Press: Boca Raton, 1987).

${ }^{21}$ Schmitz, E. Three-membered rings with two hetero atoms. Adv Heterocycl Chem 2, 83-130 (1963).

${ }^{22}$ Halloran, M. W. \& Lumb, J. Recent applications of diazirines in chemical proteomics. Chem Eur J 25, 4885-4898 (2019).

${ }^{23}$ Rostovtsev, V. V., Green, L. G., Fokin, V. V. \& Sharpless, K. B. A stepwise Huisgen cycloaddition process: Copper(I)-catalyzed regioselective "ligation" of azides and terminal alkynes. Angewandte Chemie Int Ed 41, 2596-2599 (2002).

${ }^{24}$ Lin, Y. Y., Welch, M. \& Lieberman, S. The detection of 20(S)-hydroxycholesterol in extracts of rat brains and human placenta by a gas chromatograph/mass spectrometry technique. J Steroid Biochem Mol Biol $\mathbf{8 5}$, 57-61 (2003).

25 Johnson JS, Meliton V, Kim WK, Lee K, Wang JC, Nguyen K, et al. Novel oxysterols have proosteogenic and anti-adipogenic effects in vitro and induce spinal fusion in vivo. J Cell Biochem 112, 167384 (2011).

${ }^{26}$ Pratt, H. P., Keith, J. \& Chakraborty, J. Membrane sterols and the development of the preimplantation mouse embryo. J Embryol Exp Morph 60, 303-19 (1980).

${ }^{27} \mathrm{Jao}, \mathrm{C}$. Y. et al. Bioorthogonal probes for imaging sterols in cells. Chembiochem 16, 611-7 (2015).

${ }^{28}$ Makino, T., Shibata, K., Rohrer, D. C. \& Osawa, Y. Steroid conformations in solid and solution: Stereoselectivity of Grignard addition to 20-oxo steroids. J Org Chem 43, 276-280 (1978). 
${ }^{29}$ Kalvoda, J., Heusler, K., Ueberwasser, H., Anner, G. \& Wettstein, A. 19-Norsteroide IV. Über die

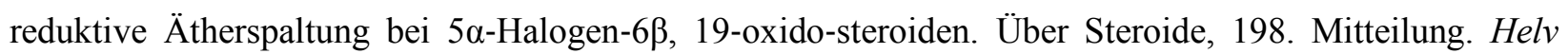
Chim Acta 46, 1361-1369 (1963).

${ }^{30}$ Brown, D. G., Velthuisen, E. J., Commerford, J. R. \& Brisbois, R. G. A convenient synthesis of dimethyl (diazomethyl)phosphonate (Seyferth/Gilbert reagent). J Org Chem 61, 2540-2541 (1996).

31 Taipale, J. et al. Effects of oncogenic mutations in Smoothened and Patched can be reversed by cyclopamine. Nature 406, 1005-1009 (2000).

32 Johnson, J. S. et al. Novel oxysterols have pro-osteogenic and anti-adipogenic effects in vitro and induce spinal fusion in vivo. $J$ Cell Biochem 112, 1673-84 (2011).

${ }^{33}$ Herz, J., Willnow, T. E. \& Farese, R. V., Jr. Cholesterol, hedgehog and embryogenesis. Nat Genet 15, 123-124 (1997).

${ }^{34}$ Schwanhäusser, B. et al. Global quantification of mammalian gene expression control. Nature 473, 337342 (2011).

${ }^{35}$ Boisvert, F.-M. et al. A Quantitative Spatial Proteomics Analysis of Proteome Turnover in Human Cells. Mol Cell Proteomics 11, M111.011429 (2012).

${ }^{36}$ Uttamapinant, C. et al. Fast, cell-Compatible click chemistry with copper-chelating azides for biomolecular labeling. Angewandte Chemie Int Ed 51, 5852-5856 (2012).

${ }^{37}$ Erickson, B. K. et al. Active instrument engagement combined with a real-time database search for improved performance of sample multiplexing workflows. J Proteome Res 18, 1299-1306 (2019).

${ }^{38}$ Tran, U., Zhang, G. C., Eom, R., Billingsley, K. L. \& Ondrus, A. E. Small molecule intervention in a Protein Kinase C-Gli transcription factor axis. ACS Chem. Biol. 15, 1321-1327 (2020).

${ }^{39}$ Kwon, H. J. et al. Structure of N-Terminal Domain of NPC1 Reveals Distinct Subdomains for Binding and Transfer of Cholesterol. Cell 137, 1213-1224 (2009).

${ }^{40}$ Ohgane, K., Karaki, F., Dodo, K. \& Hashimoto, Y. Discovery of oxysterol-derived pharmacological chaperones for NPC1: Implication for the existence of second sterol-binding site. Chem Biol 20, 391-402 (2013).

${ }^{41}$ Okamoto, Y., Ninomiya, H., Miwa, S. \& Masaki, T. Cholesterol oxidation switches the internalization pathway of Endothelin Receptor Type A from caveolae to clathrin-coated pits in Chinese Hamster Ovary Cells. J Biol Chem 275, 6439-6446 (2000).

${ }^{42}$ Budelier, M. M. et al. Photoaffinity labeling with cholesterol analogues precisely maps a cholesterolbinding site in voltage-dependent anion channel-1. J Biol Chem 292, 9294-9304 (2017).

${ }^{43}$ Kennedy, B. E., Charman, M. \& Karten, B. Niemann-Pick Type C2 protein contributes to the transport of endosomal cholesterol to mitochondria without interacting with NPC1. J Lipid Res 53, 2632-2642 (2012). 
${ }^{44}$ Walker, J. M. et al. Sigma receptors: biology and function. Pharmacol Rev 42, 355 (1990).

${ }^{45}$ Goo, Y.-H., Son, S.-H., Kreienberg, P. B. \& Paul, A. Novel lipid droplet-associated serine hydrolase regulates macrophage cholesterol mobilization. Arterio Thromb Vasc Biol 34, 386-396 (2018).

${ }^{46}$ Vogel-Bindel, U., Bentley, P. \& Oesch, F. Endogenous role of microsomal epoxide hydrolase. Eur $J$ Biochem 126, 425-431 (1982).

${ }^{47}$ Newman, J. W., Morisseau, C. \& Hammock, B. D. Epoxide hydrolases: their roles and interactions with lipid metabolism. Prog Lipid Res 44, 1-51 (2005).

${ }^{48}$ Schaafhausen, A., Rost, S., Oldenburg, J. \& Müller, C. Identification of VKORC1 interaction partners by split-ubiquitin system and coimmunoprecipitation. Thromb Haemostasis 105, 285-294 (2011).

49 Suzuki, J., Imanishi, E. \& Nagata, S. Xkr8 phospholipid scrambling complex in apoptotic phosphatidylserine exposure. Proc Natl Acad Sci USA 113, 9509-9514 (2016).

${ }^{50} \mathrm{Schmidt}$, N. et al. Neuroplastin and Basigin are essential auxiliary subunits of plasma membrane Ca2+ATPases and key regulators of Ca2+ clearance. Neuron 96, 827-838.e9 (2017).

${ }^{51}$ Fenech, E. J. et al. Interaction mapping of endoplasmic reticulum ubiquitin ligases identifies modulators of innate immune signalling. Elife 9 , e57306 (2020).

${ }^{52}$ Maxfield, F. R. \& Tabas, I. Role of cholesterol and lipid organization in disease. Nature 438, 612-621 (2005).

${ }^{53}$ Wang, Y., Yutuc, E. \& Griffiths, W. J. Neuro-oxysterols and neuro-sterols as ligands to nuclear receptors, G protein-coupled receptors, ligand-gated ion channels and other protein receptors. Brit J Pharmacol doi:10.1111/bph.15191 (2020).

${ }^{54}$ Subramanian, A. et al. Gene set enrichment analysis: A knowledge-based approach for interpreting genome-wide expression profiles. P Natl Acad Sci Usa 102, 15545-15550 (2005).

${ }^{55}$ Peyrot, S. M. et al. Tracking the subcellular fate of 20(S)-hydroxycholesterol with click chemistry reveals a transport pathway to the Golgi. J Biol Chem 289, 11095-11110 (2014).

${ }^{56}$ Mondal, M., Mesmin, B., Mukherjee, S. \& Maxfield, F. R. Sterols are mainly in the cytoplasmic leaflet of the plasma membrane and the endocytic recycling compartment in CHO cells. Mol Biol Cell 20, 581588 (2009).

${ }^{57}$ Hulce, J. J., Cognetta, A. B., Niphakis, M. J., Tully, S. E. \& Cravatt, B. F. Proteome-wide mapping of cholesterol-interacting proteins in mammalian cells. Nat Methods 10, 259-264 (2013).

${ }^{58}$ Feltes, M. et al. Synthesis and characterization of diazirine alkyne probes for the study of intracellular cholesterol trafficking. J Lipid Res 60, 707-716 (2019).

${ }^{59}$ Ridgway, N. D. 25-Hydroxycholesterol stimulates sphingomyelin synthesis in Chinese hamster ovary cells. J Lipid Res 36, 1345-1358 (1995). 
${ }^{60}$ Ghoreschi, K. et al. Generation of pathogenic TH17 cells in the absence of TGF- $\beta$ signalling. Nature 467, 967-971 (2010).

${ }^{61}$ Barbie, D. A. et al. Systematic RNA interference reveals that oncogenic KRAS-driven cancers require TBK1. Nature 462, 108-112 (2009).

${ }^{62}$ Zidovetzki, R. \& Levitan, I. Use of cyclodextrins to manipulate plasma membrane cholesterol content: Evidence, misconceptions and control strategies. Biochimica Et Biophysica Acta BBA - Biomembr 1768, 1311-1324 (2007).

${ }^{63}$ Jansen, J. C. et al. TMEM199 Deficiency is a disorder of Golgi homeostasis characterized by elevated aminotransferases, alkaline phosphatase, and cholesterol and abnormal glycosylation. Am J Hum Genetics 98, 322-330 (2016).

${ }^{64}$ Miles, A. L., Burr, S. P., Grice, G. L. \& Nathan, J. A. The vacuolar-ATPase complex and assembly factors, TMEM199 and CCDC115, control HIF1 $\alpha$ prolyl hydroxylation by regulating cellular iron levels. Elife 6, e22693 (2017).

${ }^{65}$ Margier, M. et al. ABCB1 (P-glycoprotein) regulates Vitamin D absorption and contributes to its transintestinal efflux. Faseb J 33, 2084-2094 (2019).

${ }^{66}$ Kalken, C. van et al. Cortisol is transported by the multidrug resistance gene product P-glycoprotein. Brit J Cancer 67, 284-289 (1993).

${ }^{67}$ Prokesch, A. et al. Arxes: retrotransposed genes required for adipogenesis. Nucleic Acids Res 39, 32243239 (2011).

${ }^{68}$ Sal, G. D., Ruaro, M. E., Philipson, L. \& Schneider, C. The growth arrest-specific gene, gas1, is involved in growth suppression. Cell 70, 595-607 (1992).

${ }^{69}$ Karpen, H. E. et al. The Sonic Hedgehog receptor Patched associates with caveolin-1 in cholesterol-rich microdomains of the plasma membrane. J Biol Chem 276, 19503-19511 (2001).

${ }^{70}$ Wierbowski, B. M. et al. Hedgehog pathway activation requires coreceptor-catalyzed, lipid-dependent relay of the Sonic Hedgehog ligand. Dev Cell 55, 450-467.e8 (2020).

${ }^{71}$ Rone, M. B. et al. Identification of a dynamic mitochondrial protein complex driving cholesterol import, rrafficking, and metabolism to steroid hormones. Mol Endocrinol 26, 1868-1882 (2012).

72 Darbandi-Tonkabon, R. et al. Photoaffinity labeling with a neuroactive steroid analogue. J Biol Chem 278, 13196-13206 (2003).

${ }^{73}$ Yao, L. et al. REEP5 (Receptor Accessory Protein 5) acts as a sarcoplasmic reticulum membrane sculptor to modulate cardiac function. J Am Heart Assoc 7, (2018).

${ }^{74}$ Zhou, G. L., Na, S.-Y., Niedra, R. \& Seed, B. Deficits in receptor-mediated endocytosis and recycling in cells from mice with Gpr107 locus disruption. J Cell Sci 127, 3916-3927 (2014). 
${ }^{75}$ Zeng, C., Riad, A. \& Mach, R. H. The biological function of sigma-2 receptor/TMEM97 and its utility in PET imaging studies in cancer. Cancers 12, 1877 (2020).

${ }^{76}$ Alon, A. et al. Identification of the gene that codes for the $\sigma 2$ receptor. Proc Natl Acad Sci USA 114, 7160-7165 (2017).

${ }^{77}$ Bartz, F. et al. Identification of cholesterol-regulating genes by targeted RNAi screening. Cell Metab 10, 63-75 (2009).

${ }^{78}$ Ebrahimi-Fakhari, D. et al. Reduction of TMEM97 increases NPC1 protein levels and restores cholesterol trafficking in Niemann-pick type C1 disease cells. Hum Mol Genet 25, 3588-3599 (2016).

${ }^{79}$ Alamri, M.A., Afzal, O., and Alamri, M.A. Computational screening of natural and natural-like compounds to identify novel ligands for sigma-2 receptor. Sar Qsar Environ Res 31, 837-856 (2020).

${ }^{80} \mathrm{Su}, \mathrm{T}$. P. et al. Sigma compounds derived from phencyclidine: Identification of PRE-084, a new, selective sigma ligand. J Pharmacol Exp Ther 259, 543-50 (1991).

${ }^{81}$ Bonhaus, D. W. et al. $\left[{ }^{3} \mathrm{H}\right] \mathrm{BIMU}-1$, a 5-hydroxytryptamine3 receptor ligand in NG-108 cells, selectively labels sigma-2 binding sites in guinea pig hippocampus. J Pharmacol Exp Ther 267, 961-70 (1993).

${ }^{82}$ Morisaki, M., Shikita, M. \& Ikekawa, N. Side-chain cleavage of cholesterol by gas chromatographymass spectrometry in a selected ion monitoring mode. Methods Enzymol 111, 352-364 (1985).

${ }^{83}$ Schmidt, H. R. \& Kruse, A. C. The molecular function of $\sigma$ receptors: Past, present, and future. Trends Pharmacol Sci 40, 636-654 (2019).

${ }^{84}$ Nes, W. D. et al. Purification, characterization and catalytic properties of human sterol 8-isomerase. Biochem J 367, 587-599 (2002).

${ }^{85}$ Moebius, F. F. et al. Histidine 77, glutamic acid 81, glutamic acid 123, threonine 126, asparagine 194, and tryptophan 197 of the human Emopamil Binding Protein are required for in vivo sterol $\Delta 8-\Delta 7$ isomerization. Biochemistry 38, 1119-1127 (1999).

${ }^{86}$ Long, T. et al. Structural basis for human sterol isomerase in cholesterol biosynthesis and multidrug recognition. Nat Commun 10, 2452 (2019).

${ }^{87}$ Raman, S. et al. Structure prediction for CASP8 with all-atom refinement using Rosetta. Proteins Struct Funct Bioinform 77, 89-99 (2009).

${ }^{88}$ Ravodina, A. M., Badgeley, M. A., Rajagopalan, S., Fedyukina, D. V. \& Maiseyeu, A. Facile cholesterol loading with a new probe ezFlux allows for streamlined cholesterol efflux assays. ACS Omega 5, 2328923298 (2020).

${ }^{89}$ Rodell, C. B., Mealy, J. E. \& Burdick, J. A. Supramolecular guest-host interactions for the preparation of biomedical materials. Bioconjugate Chem 26, 2279-2289 (2015)

${ }^{90}$ Kar, U. K., Simonian, M. \& Whitelegge, J. P. Integral membrane proteins: Bottom-up, top-down and structural proteomics. Expert Rev Proteomic 14, 715-723 (2017). 
${ }^{91}$ Modarelli, D. A., Morgan, S. \& Platz, M. S. Carbene formation, hydrogen migration, and fluorescence in the excited states of dialkyldiazirines. J Am Chem Soc 114, 7034-7041 (1992). 


\section{Experimental Procedures}

\section{Chemical synthesis}

Synthetic procedures and spectral data for probe 1 and $20(R)-\mathrm{OHC}$ are provided in the Supplemental Experimental Procedures.

\section{In vitro photoactivation}

A solution of $10 \mathrm{mM}$ probe 1 in DMF in a $0.2 \mathrm{~mL}$ PCR tube was irradiated using a UV crosslinker (Thermo Fisher, 13-245-221) equipped with a bank of five light tubes (F8T5/BLB, wavelength range 330-410 nm, peak wavelength $368 \mathrm{~nm}$ ). At each time point, a $1 \mu \mathrm{L}$ aliquot of the irradiated probe solution was transferred to a NanoQuant plate (Tecan). Absorbance was measured using a Spark M10 multimode plate reader (Tecan) with scanning from $280 \mathrm{~nm}$ to $550 \mathrm{~nm}$.

\section{Cell culture}

NIH-3T3 cells (ATCC, CRL-1658) and Shh-LIGHT2 cells were cultured in high-glucose DMEM (Gibco, 11965118) containing 10\% bovine calf serum (CS, ATCC, CRL-1658), $100 \mathrm{U} / \mathrm{mL}$ of penicillinstreptomycin (Gibco, 15140163), and $1 \mathrm{mM}$ sodium pyruvate (Thermo Fisher, 11360070). HEK-293T cells (ATCC, CRL-3216) were cultured in high-glucose DMEM (Gibco, 11965118) containing 10\% fetal bovine serum (FBS, Gibco, 26140079), $100 \mathrm{U} / \mathrm{mL}$ of penicillin-streptomycin (Gibco, 15140163), $1 \mathrm{mM}$ sodium pyruvate, and $2 \mathrm{mM}$ L-glutamine (Oakwood, M02960). Cells were seeded at an initial confluence of $\sim 20 \%$, passaged every 3-4 days upon reaching $75-85 \%$ confluence, and maintained in an atmosphere of $5 \% \mathrm{CO}_{2}$ and $95 \%$ humidity at $37^{\circ} \mathrm{C}$.

\section{Gel electrophoresis}

Samples were loaded on a 4-15\% PROTEAN TGX Stain-Free Protein Gel (Bio-Rad, 4568083 (Mini) or 5678084 (Midi)) with Tris/Glycine/SDS running buffer (Bio-Rad, 1610772), and proteins were resolved at a current of $125 \mathrm{~V}$ (Mini) or $150 \mathrm{~V}$ (Midi) for $1 \mathrm{~h}$ at room temperature. In-gel fluorescence and stain-free total protein signal were detected using a Bio-Rad Chemidoc MP Imaging System. Band intensities were quantified using Bio-Rad Image Lab Software v6.0.

\section{Western blot analysis}

Proteins resolved by SDS-PAGE were transferred to a PVDF membrane (0.22 $\mu \mathrm{m}$, Bio-Rad, 1620177) using a Bio-Rad Trans-Blot Turbo Transfer System (Bio-Rad, 1704273). For detecting biotinylated proteins, membranes were blocked in $0.2 \%$ I-Block (Thermo Fisher, T2015) in PBST overnight at $4{ }^{\circ} \mathrm{C}$ 
before incubating with IRDye 800CW Streptavidin (Licor, cat \# 926-32230, 1:10,000) in 0.2\% I-Block in PBST at room temperature for $1 \mathrm{~h}$ or at $4{ }^{\circ} \mathrm{C}$ overnight. For detection using primary antibodies, membranes were blocked in 2\% non-fat milk (Nestle, Carnation Instant Nonfat Dry Milk) in PBST for $1 \mathrm{~h}$ at room temperature, incubated with primary antibody in $2 \%$ non-fat milk in PBST at $4{ }^{\circ} \mathrm{C}$ overnight, rinsed $3 \times$ with PBST, incubated with secondary antibody $(1: 10,000$ in $2 \%$ non-fat milk in PBST) for $1 \mathrm{~h}$ at room temperature, and rinsed $3 \times$ with PBST. HRP-conjugated secondary antibodies were developed using Clarity Western ECL Substrate (Bio-Rad, 170506) or SuperSignal West Femto Maximum Sensitivity Substrate (Thermo Fisher, 34096). Fluorescence and chemiluminescence signals were collected using a Bio-Rad Chemidoc MP Imaging System. Band intensities were quantified using Bio-Rad Image Lab Software v6.0.

\section{Shh-LIGHT2 assays}

Shh-LIGHT2 cells were seeded in 96-well plates at a density of $3.5 \times 10^{4}$ cells/well. After $24 \mathrm{~h}$, growth media was replaced with serial dilutions of 1, 20(S)-OHC, 20(R)-OHC, or SAG (CAS no. 912545-86-9, Carbosynth, FS76762) in low-serum media (phenol red-free high-glucose DMEM (Gibco, 21063045) containing $0.5 \%$ bovine calf serum (CS, ATCC, CRL-1658), $100 \mathrm{U} / \mathrm{mL}$ of penicillin-streptomycin (Gibco, 15140163 ), and $1 \mathrm{mM}$ sodium pyruvate) at a normalized DMSO concentration of $0.2 \%$. After $30 \mathrm{~h}$, cells were washed with PBS and treated with Passive Lysis Buffer (20 $\mu \mathrm{L} /$ well, Promega, E1941) at room temperature for $15 \mathrm{~min}$ with rocking. $10 \mu \mathrm{L}$ lysate from each well was transferred to a white-bottomed assay plate (Corning, 3912) for Firefly and Renilla luciferase measurements using a Dual Luciferase Reporter kit (Promega, E1960) on a Tecan Spark M10 multimode plate reader. Gli activity was calculated as the ratio of Firefly/Renilla luciferase signal and percent Gli activation was assessed relative to DMSOonly control. Dose-response curves were generated using GraphPad Prism software.

\section{Preparation of $\mathrm{M} \beta C D$ complexes}

20(S)-OHC, 20(R)-OHC, 25-OHC, cholesterol, and inositol were dissolved in $\mathrm{MeOH}-\mathrm{CHCl}_{3}(2: 1)$ to a concentration of $10 \mathrm{mM}$ in a glass vial. Solvent was removed under a stream of nitrogen to yield a thin film on the bottom of the vial. A solution of $37.56 \mathrm{mM}$ methyl- $\beta$-cyclodextrin (MBCD) in phenol red-free DMEM was added to a final concentration of $3.76 \mathrm{mM}$, and the mixture was bath sonicated to obtain a clear solution (30 60 min). The solution was sterile-filtered through a $0.22 \mu \mathrm{m}$ PES filter (CELLTREAT, 229746), aliquoted into glass vials, and stored at $-20^{\circ} \mathrm{C}$ until use.

\section{Probe incubation and crosslinking}


For in-gel fluorescence analysis, NIH-3T3 cells were seeded at a density of $3 \times 10^{5}$ cells/well in 6-well plates (Corning, 353046) and cultured until reaching 80-90\% confluence $(\sim 24 \mathrm{~h})$. For Western Blot analysis, cells were seeded at a density of $3 \times 10^{5}$ cells/well in $10 \mathrm{~cm}$ dish (Corning, 353003) and cultured until reaching $80-90 \%$ confluence $(\sim 72 \mathrm{~h})$. For mass spectrometry analysis, NIH-3T3 cells were seeded at a density of $8 \times 10^{5}$ cells cells/well in $15 \mathrm{~cm}$ dish (Corning, 353025) and cultured until reaching 80-90\% confluence $(\sim 72 \mathrm{~h})$.

For target profiling of $\mathbf{1}$ in the absence of $\mathrm{M} \beta \mathrm{CD}$, stock solutions of compounds in DMSO or DMSO alone were diluted in serum-free media to the concentrations indicated, with DMSO concentrations normalized to $0.01 \%$. Cells were incubated with compound-containing media at $37{ }^{\circ} \mathrm{C}$ for $30 \mathrm{~min}$, washed once with ice-cold PBS, and maintained in PBS on ice. Lids were removed from plates and cells were irradiated for 5 min on ice with $365 \mathrm{~nm}$ UV light using a UV-crosslinker (Thermo Fisher, 13-245-221). For no-UV control experiments, probe-treated cells were incubated on ice for $5 \mathrm{~min}$ in ambient light.

For target profiling of $\mathbf{1}$ in the presence of $\mathrm{M} \beta C D$, stock solutions of competitor compounds in $\mathrm{M} \beta C D$ (prepared as above) or DMSO were diluted in serum-free media to the concentrations indicated and a normalized concentration of $0.5 \mathrm{mM} \mathrm{M} \beta C D$ in all samples. Cells were incubated at $37^{\circ} \mathrm{C}$ for $1 \mathrm{~h}$ before adding a $10 \times$ solution of probe 1 or DMSO to a normalized concentration of $0.01 \%$ DMSO in all samples. Cells were incubated at $37^{\circ} \mathrm{C}$ for another $30 \mathrm{~min}$, then rinsed and irradiated as above.

\section{Cell harvest and subcellular fractionation}

After crosslinking, cells were detached by scraping in cold PBS and collected by centrifugation at $4{ }^{\circ} \mathrm{C}$ and $750 \times \mathrm{g}$ for $5 \mathrm{~min}$. Cell pellets were washed $2 \times$ by resuspension in ice-cold PBS and centrifugation, then snap-frozen in liquid $\mathrm{N}_{2}$ and stored at $-80{ }^{\circ} \mathrm{C}$ before further processing. Subcellular fractionation was conducted according to Baghirova et al. ${ }^{1}$ Namely, cell pellets were resuspended in ice cold lysis buffer A (50 mM HEPES, pH 7.4; 150 mM NaCl; 1 M hexylene glycol; $25 \mu \mathrm{g} / \mathrm{ml}$ digitonin; and 1× cOmplete EDTAfree Protease Inhibitor Cocktail (Roche, 11836170001)) and incubated using an end-over-end rotator for $10 \mathrm{~min}$ at $4{ }^{\circ} \mathrm{C}$. Lysate was centrifuged at $2000 \times \mathrm{g}$ for $10 \mathrm{~min}$ at $4{ }^{\circ} \mathrm{C}$ and the supernatant was collected as the cytosolic fraction. Pellets were suspended in ice cold lysis buffer B (50 mM HEPES, pH 7.4; 150 $\mathrm{mM} \mathrm{NaCl} ; 1 \mathrm{M}$ hexylene glycol; 1\% IGEPAL-CA630; and 1× cOmplete EDTA-free Protease Inhibitor Cocktail) and resuspended by vortexing. The suspension was incubated on an end-over-end rotator for 30 min at $4{ }^{\circ} \mathrm{C}$ and centrifuged at $7000 \times \mathrm{g}$ for $10 \mathrm{~min}$ at $4{ }^{\circ} \mathrm{C}$. The supernatant was collected as the membrane fraction. The remaining pellet was suspended in ice cold lysis buffer C (50 mM HEPES, pH 7.4; $150 \mathrm{mM}$ $\mathrm{NaCl} ; 1 \mathrm{M}$ hexylene glycol; $0.5 \%$ sodium deoxycholate; $0.1 \% \mathrm{SDS} ; 25 \mathrm{U} / \mathrm{mL}$ benzonase; and $1 \times$ cOmplete EDTA-free Protease Inhibitor Cocktail), resuspended by vortexing, and incubated for $20 \mathrm{~min}$ on an endover-end rotator at $4{ }^{\circ} \mathrm{C}$. The suspension was pelleted at $7800 \times \mathrm{g}$ for $10 \mathrm{~min}$ at $4{ }^{\circ} \mathrm{C}$, and the resulting 
supernatant was collected as the nuclear fraction. Protein concentrations of each fraction were determined using the BCA protein assay (Thermo Fisher, 23227).

\section{Click reaction}

Membrane fractions from all samples in each experiment were normalized to the same protein concentration ( $\sim 40-60 \mu \mathrm{g}$ for gel-based analysis, $\sim 600-900 \mu \mathrm{g}$ for mass spectrometry analysis) by diluted in fractionation lysis buffer. A solution of azide in DMSO was added to a concentration of $25 \mu \mathrm{M}$ TAMRA azide (Click Chemistry Tools, AZ109) or $100 \mu \mathrm{M}$ picolyl biotin azide (Click Chemistry Tools, 1167), followed by a freshly prepared catalyst mixture containing TBTA (102 $\mu \mathrm{M}$, from a $1.7 \mathrm{mM}$ stock in 4:1 DMSO:t-BuOH), $\mathrm{CuSO}_{4}\left(1 \mathrm{mM}\right.$, from a $50 \mathrm{mM}$ stock in $\left.\mathrm{H}_{2} \mathrm{O}\right)$, and TCEP $(1 \mathrm{mM}$, from a $50 \mathrm{mM}$ stock in PBS, adjusted to $\mathrm{pH} 7 \sim 8$ immediately before use). After incubating on an end-over-end rotator for $1 \mathrm{~h}$ at room temperature, each reaction was diluted with 4 volumes of cold acetone $\left(-20^{\circ} \mathrm{C}\right)$, vortexed briefly, and maintained at $20{ }^{\circ} \mathrm{C}$ for $30 \sim 60 \mathrm{~min}$. Precipitate was pelleted at $20,000 \times \mathrm{g}$ for $10 \mathrm{~min}$ at $4{ }^{\circ} \mathrm{C}$, resuspended in acetone by brief bath-sonication, and maintained at $-20{ }^{\circ} \mathrm{C}$ for $10 \sim 30 \mathrm{~min}$ two times. After removing the supernatant, the pellet was air dried at RT for 5 10 min.

\section{In-gel fluorescence analysis}

For fluorophore-conjugated samples, dried pellets from acetone precipitation were resuspended in equal volumes of 1\% SDS in PBS and 1\% IGEPEL CA-630 in PBS containing 1× cOmplete EDTA-free Protease Inhibitor Cocktail, and $1 \times$ SDS sample buffer (from $6 \times$ SDS sample buffer, which contains $300 \mathrm{mM}$ Tris$\mathrm{HCl}$, pH6.8, 50\% (v/v) glycerol, 12\% (w/v) SDS, $600 \mathrm{mM}$ DTT and 0.6 g/L bromophenol blue). Samples were bath sonicated for 3 5 min, incubated on a Thermomixer (Eppendorf, 5350) for $30 \mathrm{~min}\left(50{ }^{\circ} \mathrm{C}, 950\right.$ rpm) and subjected to SDS-PAGE.

\section{Streptavidin enrichment}

For biotin-conjugated samples, dried pellets from acetone precipitation were resuspended in equal volumes of 1\% SDS in PBS and 1\% IGEPEL CA-630 in PBS (containing 1× cOmplete EDTA-free Protease Inhibitor Cocktail) by bath sonication (3 5 min) before diluting to a final concentration of $0.1 \%$ SDS and $1 \%$ IGEPEL CA-630 in PBS (containing 1× cOmplete EDTA-free Protease Inhibitor Cocktail). The diluted solution was bath-sonicated for 3 5 min and centrifuged at 7,000 $\times \mathrm{g}$ at RT for $3 \mathrm{~min}$ to pellet any insoluble proteins. The supernatant was transferred to a $1.7 \mathrm{~mL}$ tube containing streptavidin agarose (Thermo Fisher, 20349, 50\% slurry, pre-washed twice with PBS). The mixture was incubated on an end-over-end rotator overnight $(12 \sim 16 \mathrm{~h})$ at room temperature. The suspension was transferred to a Pierce centrifuge column (Thermo Fisher, $0.8 \mathrm{~mL}$ ) and centrifuged at $1,000 \times \mathrm{g}$ at RT for $1 \mathrm{~min}$. The flow-through was discarded, 
and the resin was washed $3 \times$ with Wash Buffer containing 1\% IGEPEL CA630, 0.1\% SDS in PBS and transferred to a new $1.7 \mathrm{~mL}$ tube in Wash Buffer. The suspension was centrifuged at 2,500 $\times \mathrm{g}$ at RT for 1 min and the supernatant was discarded.

For SDS-PAGE/Western blot analysis, proteins were eluted by incubating the resin in $1 \times$ SDS sample buffer containing $2 \mathrm{mM}$ biotin for $30 \mathrm{~min}$ at $50{ }^{\circ} \mathrm{C}$. For mass spectrometry analysis, proteins bound to the resin were directly subjected to on-bead digestion.

\section{Mass spectrometry sample preparation}

On-bead digestion. After enrichment, streptavidin agarose was resuspended in $6 \mathrm{M}$ urea in PBS, reduced with $10 \mathrm{mM}$ DTT for $1 \mathrm{~h}$ at room temperature, and alkylated with $25 \mathrm{mM}$ iodoacetamide on an end-overend rotator in the dark for $30 \mathrm{~min}$ at room temperature. Beads were pelleted at 2,500 $\times \mathrm{g}$ for $1 \mathrm{~min}$, the supernatant was removed, and the beads were washed $2 \times$ with PBS and resuspended in $2 \mathrm{M}$ urea in PBS. Trypsin $(1.5 \mu \mathrm{g})$ (Promega, V5111) and $1 \mathrm{mM} \mathrm{CaCl}_{2}$ were added to the samples and digestion was performed for $12-16 \mathrm{~h}$ at $37{ }^{\circ} \mathrm{C}$ on a Thermomixer. Supernatant was collected and the beads were washed with water and 50\% acetonitrile. The washes were combined and concentrated to dryness using a CentriVac concentrator (Labconco, 7310022).

Sample desalting. Dried peptides from the trypsin digest were resuspended in buffer A $\left(98 \% \mathrm{H}_{2} \mathrm{O}, 2 \%\right.$ acetonitrile, $0.2 \%$ formic acid) and desalted using a StageTip (homemade from Empore C18 Extraction disks, 3M, 2215, $200 \mu \mathrm{L}$ Pipette tip, $\sim 20 \mu \mathrm{g}$ capacity) pre-equilibrated first with acetonitrile and then with buffer A. The sample-loaded StageTip was washed with buffer A and subsequently eluted with elution buffer 1 ( $50 \%$ acetonitrile, $50 \% \mathrm{H}_{2} \mathrm{O}, 0.2 \%$ formic acid). For TMT labeling, peptides were further eluted with elution buffer $2 \mathrm{~A}\left(80 \%\right.$ acetonitrile, $20 \% \mathrm{H}_{2} \mathrm{O}, 0.2 \%$ formic acid). For label-free quantification, peptides were further eluted with elution buffer $2 \mathrm{~B}\left(75 \%\right.$ acetonitrile, $25 \% \mathrm{H}_{2} \mathrm{O}, 0.2 \%$ formic acid). Desalted samples were concentrated to dryness using a CentriVac concentrator and stored at $-80{ }^{\circ} \mathrm{C}$.

TMT labeling. Dried, desalted peptides from the trypsin digest were resuspended in $50 \mu \mathrm{L}$ of $100 \mathrm{mM}$ triethylammonium bicarbonate (TEAB, $\mathrm{pH} 8.5$ ) and $20 \mu \mathrm{L}$ of a $20 \mu \mathrm{g} / \mu \mathrm{L}$ solution of TMT 6-plex (Thermo Fisher, 90061) or 10-plex isobaric label reagent (Thermo Fisher, 90110) in anhydrous acetonitrile. Labeling reactions were incubated at room temperature for 2 hour on a Thermomixer $(650 \mathrm{rpm})$. A label efficiency check was performed by withdrawing $0.4 \mu \mathrm{L}$ from each sample within a single plex to ensure at least $98 \%$ labeling of all $\mathrm{N}$-termini and lysine residues. Reactions were quenched with $4 \mu \mathrm{L}$ of $5 \%$ hydroxylamine at room temperature for $15 \mathrm{~min}$. TMT-labeled peptides from all samples were combined and concentrated to dryness using a CentriVac concentrator. 
Sample desalting and TMT reagent removal. The dried, combined, TMT-labeled peptides were resuspended in $200 \mu \mathrm{L}$ buffer $\mathrm{A}\left(98 \% \mathrm{H}_{2} \mathrm{O}, 2 \%\right.$ acetonitrile, $0.2 \%$ formic acid) and desalted using an Agilent 1100 HPLC with an Optimized Technologies C4 peptide Macrotrap (3 x 8 mm; $200 \mu \mathrm{g}$ maximum capacity). The mobile phase consisted of $98 \% \mathrm{H}_{2} \mathrm{O}, 2 \%$ acetonitrile, $0.2 \%$ formic acid (solvent A) and $95 \%$ $\mathrm{ACN} / 0.1 \% \mathrm{FA}$ (solvent $\mathrm{B}$ ) delivered at a flow rate of $250 \mu \mathrm{L} / \mathrm{min}$ with the following gradient: 0-10 min, $0 \% \mathrm{~B} ; 10-12 \mathrm{~min}, 0-85 \% \mathrm{~B}$; $12-17 \mathrm{~min}, 85 \% \mathrm{~B}$; 17-18 min, 85-90\% B; 18-23 $\min 90 \% \mathrm{~B}$; 23-24 min, 90100\% B; 24-30 min, 100\% B. (Post time: $5 \mathrm{~min}, 0 \% \mathrm{~B}$ and $200 \mu \mathrm{L} / \mathrm{min}$ ). The fraction between 12-15 min was collected and concentrated to dryness using a CentriVac concentrator and stored at $-80^{\circ} \mathrm{C}$ before LCMS/MS analysis at the Beckmann Institute Proteome Exploration Laboratory at Caltech. Full details of LC-MS/MS and LC-MS/MS/MS are provided in the Supplementary Information.

TMT labeling quantification. Proteomics data analysis was performed in Proteome Discoverer 2.4 (Thermo Scientific). Spectra were filtered for HCD spectra with signal-to-noise $>1.5$. Spectra were searched against Reviewed proteins in the Uniprot mouse proteome (UP000000589, downloaded July 2020) and common contaminant proteins (Maxquant contaminants database, downloaded July 2020) using SEQUEST HT search algorithm. SEQUEST HT search parameters were as follows: fully Tryptic peptides with no more than 2 missed cleavages, precursor mass tolerance of $10 \mathrm{ppm}$ and fragment mass tolerance of $0.6 \mathrm{Da}$, and a maximum of 3 equal modifications and 4 dynamic modifications per peptide. Static modifications were carbamidomethylation of cysteine $(+57.021464 \mathrm{Da})$ and TMT6plex addition to lysines and peptide N-termini (+229.162932 Da). Oxidation on methionine residues (+15.994915 Da), methionine loss on protein N-termini $(-131.040485 \mathrm{Da})$, methionine loss + acetylation on protein N-termini $(-89.02992 \mathrm{Da})$, acetylation on protein N-termini (+42.010565 Da), and phosphorylation of serine, threonine, and tyrosine (+79.966331 Da) were dynamic modifications. Percolator FDRs were set at 0.01 (strict) and 0.05 (relaxed). Spectrum file retention time calibration was used with TMT6plex addition to peptide N-termini and lysines and carbamidomethylation of cysteine as static modifications. Reporter ion quantification used a co-isolation threshold of 100, average reporter $\mathrm{S} / \mathrm{N}$ threshold of 5 , and SPS mass match threshold of 70\%. Peptide FDRs were set at 0.001 (strict) and 0.01 (relaxed), with peptide confidence at least medium, lower confidence peptides excluded, and minimum peptide length set at 6 .

Data analysis. Non-normalized abundance values of proteins from Proteome Discoverer were $\log _{2}$ transformed before further analysis. Missing values were imputed within treatment groups using the MinProb (Probabilistic Minimum Imputation) method embedded in the imputeLCMD R package. $\log _{2}$ fold 
changes were calculated from the differences in the means of replicates between groups. The statistical significance of differences between groups was assessed using a two-tailed unpaired t-test.

\section{Analysis of probe-labeled YFP-mSmo in HEK-293T cells}

Protein in the membrane fraction of each sample was normalized to $\sim 60 \mu \mathrm{g}$ and transferred to a $1.7 \mathrm{~mL}$ tube containing pre-washed GFP-Trap ${ }^{\circledR}$ magnetic agarose beads (Chromotek, gtma, washed twice in PBS). The suspension was incubated on an end-over-end rotator for $3 \mathrm{~h}$ at $4{ }^{\circ} \mathrm{C}$. The beads were separated with a magnetic rack (Thermo Fisher, DynaMag-2 Magnet, 12321D) and washed three times with cold 0.1\% IGEPAL CA-630 in PBS. The beads were resuspended in 1\% SDS in PBS and subjected click reaction using the conditions described above. After the reaction, beads were separated with a magnet and washed three times with PBS. Proteins were eluted by resuspending the beads in $1 \%$ SDS in PBS and $2 \times$ SDS sample buffer, bath-sonication (3 5 min), and incubation on a Thermomixer for $20 \mathrm{~min}\left(50{ }^{\circ} \mathrm{C}, 450 \mathrm{rpm}\right)$. The eluate was was transferred to a new tube and the elution was repeated once. The eluate fractions were combined, YFP-Smo and GFP expression was assessed by SDS-PAGE and in-gel fluorescence, and proteins were transferred to a PVDF membrane for detection of biotinylated proteins.

\section{Gene Set Enrichment Analysis (GSEA)}

GSEA was performed using GSEA desktop version 4.1.0. ${ }^{2}$ Datasets with $\log _{2}$-transformed fold changes were analyzed using the C5 (Gene ontology), C6 (Oncogenic signatures) or C7 (Immunologic signatures) gene set collections in the Molecular Signatures Database (MSigDB v. 7.2). The number of permutations was set to 1000 for p-value calculation and permutation type was set to gene_set. All basic and advanced fields were set to default.

\section{Generation of Tmem97 knockout cell lines}

Guide plasmid cloning. A guide RNA target sequence in exon 1 of mouse Tmem97 was identified using Benchling tools. ${ }^{3,4,5}$ Oligonucleotides with the sgRNA sequence and adaptor overhangs were ordered from IDT and annealed in annealing buffer (100 mM potassium acetate, $30 \mathrm{mM}$ HEPES-KOH pH 7.4, 2 $\mathrm{mM}$ magnesium acetate) for $5 \mathrm{~min}$ at $95{ }^{\circ} \mathrm{C}$ with cooling to $\mathrm{RT}$ over $45 \mathrm{~min}$. Annealed oligos were phosphorylated using T4 polynucleotide kinase (New England Biolabs, M0201) and ligated into the BbsI restriction site of the linearized pU6-(BbsI)_CBh-Cas9-T2A-mCherry plasmid (Addgene, 64324) using T4 DNA ligase (New England Biolabs, M0202). Oligonucleotide sequences are provided in Table S1.

NIH-3T3 cell guide transfection and FACS. NIH-3T3 Cells were seeded at a density of $1.5 \times 10^{6}$ cells/10 $\mathrm{cm}$ plate $24 \mathrm{~h}$ before transfection. After reaching approximately $80 \sim 85 \%$ confluence, cells were transfected 
with $14 \mu \mathrm{g}$ plasmid DNA, which was precomplexed with Lipofectamine 2000 (Thermo Fisher, 11668019) at a ratio of 1:2.5 DNA:Lipo2000 (w/w) in Opti-MEM reduced serum media (Thermo Fisher, 51985034) for $10 \mathrm{~min}$ before adding dropwise to the cells. Cells were cultured for an additional $42-48 \mathrm{~h}$, trypsinized, and sorted by mCherry fluorescence on a Sony SY3200 Cell Sorter at the Caltech Flow Cytometry Core. Cells in the top $1 \%$ mCherry fluorescence were re-seeded into 96 -well plates to achieve $\sim 1$ cell/well and expanded.

TIDE analysis of knockout efficiency. Genomic DNA was extracted from cells using the DNeasy blood and tissue kit (QIAGEN, 69504) according to manufacturer's instructions. The primers for TIDE analysis were designed according to protocol recommendations ${ }^{6}$ (see Table $\mathrm{S} 1$ for primer sequences). PCR reactions were performed on $50 \mathrm{ng}$ isolated genomic DNA extract using Phusion High-Fidelity DNA Polymerase in Phusion HF buffer (New England Biolabs, M0531) in a final volume of $25 \mu \mathrm{L}$. PCR products were purified using QIAquick PCR Purification Kit (QIAGEN, 28104) according to manufacturer's instructions and analyzed by Sanger sequencing. The publicly available TIDE program was used to determine knockout efficiency for each cell line (https://tide.nki.nl, accessed December 2020).

\section{Site-directed mutagenesis}

Myc-DDK-tagged mouse transmembrane protein 97 (Tmem97, NP_133706) in the pCMV6 vector was obtained from Origene (MR201535) and used for site-directed mutagenesis to create E61A, F88A, W95A, and Y150A mutants. PCR reactions were performed using Phusion High-Fidelity 2X Master Mix (New England Biolabs, M0531) and parent constructs were digested with DpnI (New England Biolabs, R0176). All primer sequences are available in Table S1.

\section{Overexpression of Tmem97 and mutants HEK-293T cells}

HEK-293T cells were seeded at a density of $2.5 \times 10^{5}$ cells/well in a 6-well plate $24 \mathrm{~h}$ before transfection. After reaching approximately $60 \sim 70 \%$ confluence, cells were transfected with $2 \mu \mathrm{g}$ DNA precomplexed with polyethylenimine $(\mathrm{PEI})$ at a ratio of 1:3 DNA:PEI (w/w) in Opti-MEM reduced serum media for 30 min. Transfected cells were cultured for $42-48 \mathrm{~h}$ before compound treatment.

\section{Tmem97 homology modeling, 20(S)-OHC docking, and molecular dynamics analysis}

The Robetta prediction server was used to generate a homology model for TMEM97 based on the cryo-EM structure of human 3 $\beta$-hydroxysteroid- $\Delta(8), \Delta(7)$-isomerase (NP_006570.1) complexed with the inhibitor U18666A (PDB 6OHT). Ligand-docking studies were performed using the Glide software in Maestro (Schrödinger, Version 12.5.139). Protein energy minimization and assignment of hydrogen bonds were 
performed using the OPSL3e force field. The 20(S)-OHC binding site was refined using the Receptor Grid Generation script in Glide.

Ten conformers of 20(S)-OHC were generated using the Python library ETKDG, ${ }^{7}$ included in the cheminformatics Python library rdkit. $^{8}$ Docking poses for $20(S)$-OHC conformers in the Tmem97 model were predicted using Glide via the Ligand Docking script. Rigid ligand sampling was specified to retain the ligand conformations obtained from ETKDG and standard precision was used. The ligand conformers were permitted to dock anywhere within the cavity or on the exterior surface of the protein, and up to five docking poses per ligand were generated. The docking pose with the best Glide score, which docked the ligand in the internal cavity of the protein, was selected for molecular dynamics analysis.

\section{Molecular dynamics simulations}

The Tmem 97 protein, POPC, and ions were parameterized using the CHARMM36m force field, with water as described in the TIP3P model. ${ }^{9,10}$ The temperature was maintained at $310 \mathrm{~K}$ using a Nosé-Hoover ${ }^{11,12}$ thermostat with a damping constant of $1.0 \mathrm{ps}$ for temperature coupling, and the pressure was controlled at 1 bar using the Parrinello-Rahman barostat algorithm ${ }^{13}$ with a $5.0 \mathrm{ps}$ damping constant for the pressure coupling. Semi-isotropic pressure coupling was used throughout the calculations. The Lennard-Jones cutoff radius was $12 \AA$, where the truncated non-bonded forces at the cutoff distance was smoothly shifted to 0 after $10 \AA$ using a force-switch function. Periodic boundary conditions were applied in all three directions. The Particle Mesh Ewald algorithm ${ }^{14}$ with a real cutoff radius of $12 \AA$ and a grid spacing of 1.2 $\AA$ was used to calculate the long-range coulombic interactions. A compressibility of $4.5 \times 10^{-5}$ bar $^{-1}$ was used along the xy-plane and the $\mathrm{z}$ axis to relax the box volume. In all of the above simulations, water $\mathrm{OH}-$ bonds were constrained by the SETTLE algorithm. ${ }^{15}$ The remaining H-bonds were constrained using the P-LINCS algorithm. ${ }^{16}$ A simulation time step of 2 fs was used for integrating the equation of motions. All simulations were performed using GROMACS-2019.4 $4^{17,18}$ and the constrained dynamics simulations were done using PLUMED-2.5. ${ }^{19}$ The membrane-embedded Tmem97 protein was optimized using 1000 steps of energy minimization according to the GROMACS steepest descent algorithm ${ }^{17,30}$ followed by an MD simulation in a canonical ensemble, where the system was heated from $0 \mathrm{~K}$ to $310 \mathrm{~K}$ for $155 \mathrm{ps}$. Next, an MD simulation in an isobaric-isothermal ensemble was performed with positional restraints on heavy atoms using a force constant of $9.6 \mathrm{kcal} . \mathrm{mol}^{-1} \AA^{-2}$ for $2.25 \mathrm{~ns}$. The z-coordinates of the POPC headgroups were restrained inside the membrane with a force constant of $\sim 2.4 \mathrm{kcal}^{\mathrm{mol}} \mathrm{m}^{-1} \AA^{-2}$, while the POPC molecules were allowed to move freely along the xy-plane. Restraints on the protein and POPC molecules were progressively reduced to $0 \mathrm{kcal} . \mathrm{mol}^{-1} \AA^{-2}$. The system was equilibrated by performing an MD simulation at a temperature of $310 \mathrm{~K}$ and pressure of 1 bar for $10 \mathrm{~ns}$. 


\section{Methods references}

${ }^{1}$ Baghirova, S., Hughes, B. G., Hendzel, M. J. \& Schulz, R. Sequential fractionation and isolation of subcellular proteins from tissue or cultured cells. MethodsX 2, 440-445 (2015).

${ }^{2}$ Subramanian, A. et al. Gene set enrichment analysis: A knowledge-based approach for interpreting genome-wide expression profiles. P Natl Acad Sci USA 102, 15545-15550 (2005).

${ }^{3}$ http://benchling.com/, accessed August 2020.

${ }^{4}$ Doench, J., Fusi, N., Sullender, M. et al. Optimized sgRNA design to maximize activity and minimize off-target effects of CRISPR-Cas9. Nat Biotechnol 34, 184-191 (2016).

${ }^{5}$ Hsu, P., Scott, D., Weinstein, J. et al. DNA targeting specificity of RNA-guided Cas9 nucleases. Nat Biotechnol 31, 827-832 (2013).

${ }^{6}$ Brinkman, E. K., Chen, T., Amendola, M. \& van Steensel, B. Easy quantitative assessment of genome editing by sequence trace decomposition. Nucleic Acids Res 42, e168-e168 (2014).

${ }^{7}$ Riniker, S. \& Landrum, G. A. Better informed distance geometry: Using what we know to improve conformation generation. J Chem Inf Model 55, 2562-2574 (2015).

${ }^{8}$ Landrum, G. RDKit: Open-Source Cheminformatics http://www.rdkit.org (GitHub and SourceForge, accessed November 2020).

${ }^{9}$ Huang, J., Rauscher, S., Nawrocki, G., Ran, T., Feig, M., de Groot, B.L., Grubmüller, H. \& MacKerell, A.D. CHARMM36m: an improved force field for folded and intrinsically disordered proteins. Nat Methods 14, 71-73 (2017).

${ }^{10}$ Jorgensen, W.L., Chandrasekhar J, Madura JD, Impey RW, Klein ML. Comparison of simple potential functions for simulating liquid water. 1983. J Chem Phys 79(2):926-935.

${ }^{11}$ Nosé, S. A molecular dynamics method for simulations in the canonical ensemble. Mol Phys 52, 255268 (1984).

${ }^{12}$ Hoover, W. G. Canonical dynamics: Equilibrium phase-space distributions. Phys Rev A 31, 1695-1697 (1985).

${ }^{13}$ Parrinello, M. \& Rahman, A. Polymorphic transitions in single crystals: A new molecular dynamics method. J Applied Phys 52, 7182-7190 (1981).

${ }^{14}$ Essmann, U. et al. A smooth particle mesh Ewald method. J Chem Phys 103, 8577-8593 (1995).

${ }^{15}$ Miyamoto, S. \& Kollman, P. A. Settle: An analytical version of the SHAKE and RATTLE algorithm for rigid water models. J Comput Chem 13, 952-962 (1992).

${ }^{16}$ Hess, B. P-LINCS: A parallel linear constraint solver for molecular simulation. J Chem Theory Comput 4, 116-122 (2007). 
${ }^{17}$ Abraham, M. J. et al. GROMACS: High performance molecular simulations through multi-level parallelism from laptops to supercomputers. SoftwareX 1-2, 19-25 (2015).

${ }^{18}$ Pronk, S. et al. GROMACS 4.5: a high-throughput and highly parallel open source molecular simulation toolkit. Bioinformatics 29, 845-854 (2013).

${ }^{19}$ Tribello, G. A., Bonomi, M., Branduardi, D., Camilloni, C. \& Bussi, G. PLUMED 2: New feathers for an old bird. Comput Phys Commun 185, 604-613 (2014). 


\section{Main figure captions}

Fig. 1: Design, synthesis, and evaluation of 20(S)-OHC chemoproteomics probe 1.

a. Structures of 20(S)-hydroxycholesterol $(20(S)-\mathrm{OHC})$ and the photoactivable, clickable analogue 1, which contains a diazirine at $\mathrm{C} 25$ for photocrosslinking and an alkyne at $\mathrm{C} 19$ for click chemistry.

b. Chemical synthesis of probe 1. Conditions: $a$. NBA, aq. $\mathrm{HClO}_{4}, 1,4-$ dioxane, $0 \rightarrow 23{ }^{\circ} \mathrm{C}, 77 \% ; b$. $\mathrm{Pb}(\mathrm{OAc})_{4}, \mathrm{CaCO}_{3}, \mathrm{I}_{2}, \mathrm{~h} v$, cyclohexane, $80{ }^{\circ} \mathrm{C},>99 \%$; $c$. $\mathrm{Zn}, \mathrm{AcOH}-\mathrm{H}_{2} \mathrm{O}, 45{ }^{\circ} \mathrm{C}, 88 \%$; $d$. PCC, Celite, $\mathrm{CH}_{2} \mathrm{Cl}_{2}, 23{ }^{\circ} \mathrm{C}, 87 \%$; e. (i) Seyferth-Gilbert reagent, t-BuOK, THF, $-78{ }^{\circ} \mathrm{C}, 80 \%$; (ii) $\mathrm{Cs}_{2} \mathrm{CO}_{3}, \mathrm{MeOH}$, $23{ }^{\circ} \mathrm{C},>99 \%$; f. 2-(3-bromopropyl)-2-methyl-1,3-dioxolane, $\mathrm{Mg}$, THF, $0 \rightarrow 23{ }^{\circ} \mathrm{C}, 66 \%$; . HCl, THF, $23{ }^{\circ} \mathrm{C}, 94 \%$; $h$. (i) $\mathrm{NH}_{3}, \mathrm{MeOH}, 0{ }^{\circ} \mathrm{C}$; (ii) $\mathrm{NH}_{2} \mathrm{HSO}_{3}, 0 \rightarrow 23{ }^{\circ} \mathrm{C}$; (iii) $\mathrm{I}_{2}, \mathrm{Et}_{3} \mathrm{~N}, \mathrm{THF}, 23{ }^{\circ} \mathrm{C}, 46 \%$.

c. Irradiation of probe $1(10 \mathrm{mM}, \mathrm{DMF})$ with $368 \mathrm{~nm}$ light results in loss of diazirine absorption at 353 $\mathrm{nm}$ with a half-life of 1.4 minutes. Values are the average of triplicate measurements \pm s.d.

d. Treatment of Shh-LIGHT2 cells with 20(S)-OHC, 20(R)-OHC, or probe 1 demonstrates that 20(S)OHC and 1, but not the inactive epimer $20(R)-\mathrm{OHC}$, activate the Smoothened-regulated Gli transcription factors. Values are the average of 3 biological replicates \pm s.d.

e. Left: In-gel fluorescence analysis of membrane fractions from HEK293T cells overexpressing YFPSmo or GFP. Live cells were treated with 1 or DMSO and irradiated, then YFP-Smo or GFP were isolated from membrane fractions using a GFP nanobody that binds both fluorescent proteins. Isolated proteins were subjected to a click reaction to biotinylate crosslinked proteins. Right: Detection of biotinylated proteins using Streptavidin IRDye 800CW (Strept-IR) demonstrates that 1treated YFP-Smo-expressing cells are labeled with biotin. YFP-Smo-expressing cells treated with DMSO and GFP-expressing cells treated with 1 show no biotin labeling.

\section{Fig. 2: Probe 1 labels membrane proteins in live NIH-3T3 cells.}

a. Workflow for gel-based profiling of probe 1 target proteins. Cells are incubated for 30 min with 1 $\mu \mathrm{M} 1$, DMSO, or $1 \mu \mathrm{M} 1+50 \mu \mathrm{M} 20(S)-\mathrm{OHC}$ and irradiated for $5 \mathrm{~min}$ with $368 \mathrm{~nm}$ light. Isolated membrane fractions are subjected to a click reaction with TAMRA azide, separated by SDS-PAGE, and identified by in-gel fluorescence.

b. Control experiments demonstrate that fluorescent labeling requires treatment with 1, exposure to UV light, and click ligation to TAMRA. In "no 1", cells were incubated with DMSO only; in "no UV"; probe-treated cells were not exposed to $368 \mathrm{~nm}$ light; in "no $\mathrm{Cu}$ ", $\mathrm{CuSO}_{4}$ was omitted from the click reaction; in "no $\mathrm{N}_{3}$ ", TAMRA azide was omitted from the click reaction. 
c. Cell fractionation shows that TAMRA-labeled proteins appear primarily in the membrane fraction, as opposed to cytosolic or nuclear fractions. The Sodium/potassium-transporting ATPase subunit alpha$1(\mathrm{Na} / \mathrm{K}$ ATPase) was used as a membrane marker.

d. Proteins in the membrane fraction are labeled by $\mathbf{1}$ in a dose-dependent manner.

e. Competition by $20(S)-\mathrm{OHC}$ during incubation of cells with 1 reduces TAMRA labeling of a $21 \mathrm{kDa}$ band in a dose-dependent manner.

Fig. 3: Protein targets of probe 1 converge in distinct gene ontologies and disease signatures.

a. Workflow for MS-based profiling of probe 1 target proteins. Cells are incubated for 30 min with 1 $\mu \mathrm{M} 1$ or DMSO and irradiated for 5 min with $368 \mathrm{~nm}$ light. Isolated membrane fractions are subjected to a click reaction with biotin picolyl azide, enriched with streptavidin agarose, and digested with trypsin. Digested peptides from each sample are labeled with unique isobaric mass tags, then samples are pooled and analyzed by LC/RTS-SPS-MS ${ }^{3}$. Data represent of 4 biological replicates of matched experiments with $\mathbf{1}$ and DMSO.

b. Volcano plot showing statistical significance versus average $\log _{2}$ (fold change) (" $\log _{2}$ (enrichment)") of peptides isolated from cells treated with 1 or DMSO alone. Cutoffs discussed in the text at a pvalue of 0.002 and fold changes of 25 and 10 are indicated. See also Fig S1, Fig S2A,B,C, and File S1.

c. Gene Set Enrichment Analysis (GSEA) of 1-enriched proteins using Gene Ontology (GO) gene set. The top 16 GO pathways ranked by NES (Normalized Enriched Score) are listed. Bubbles are colored according to GO term class; bubble size is proportional to the number of $\mathbf{1}$-enriched proteins found in each gene set.

(d),(e) GSEA using the immunologic (D) and oncogenic (E) signature gene sets for 1-enriched proteins. Enriched proteins the leading edge of the gene set are listed below; color and size of the bubbles represent $\log _{2}$ (enrichment) and $-\log (\mathrm{p}$-value), respectively.

Fig. 4: 20(S)-OHC identifies enriched and competable probe 1 target proteins.

a. Workflow for MS-based profiling of probe 1 target proteins. Cells are preincubated with $50 \mu \mathrm{M}$ $20(S)-\mathrm{OHC}$ complexed with M $\beta \mathrm{CD}$ or M $\beta \mathrm{CD}$ alone for $1 \mathrm{~h}$ before addition of $1 \mu \mathrm{M}$ probe 1 or DMSO and incubation for $30 \mathrm{~min}$. Cells are irradiated for 5 min with $368 \mathrm{~nm}$ light, then isolated membrane fractions are subjected to a click reaction with biotin picolyl azide, enriched with streptavidin agarose, and digested with trypsin. Digested peptides from each sample are labeled with unique isobaric mass tags, then samples are pooled and analyzed by LC/RTS-SPS-MS ${ }^{3}$. Data represent 3 biological replicates of matched experiments with 1, 1 +20(S)-OHC, and DMSO. 
b. Venn diagram of proteins enriched by probe $\mathbf{1}$ in the presence and absence of M $\beta C D$. See also Fig. S3a,b,c.

c. Volcano plot showing statistical significance versus average $\log _{2}$ (fold change) (" $\log _{2}$ (enrichment)") of peptides isolated from cells treated with $1 \mu \mathrm{M} 1$ or DMSO alone. Cutoffs discussed in the text at a p-value of 0.05 and fold changes of 7 and 2.5 are indicated. See also File S1.

d. Volcano plot showing statistical significance versus average $\log _{2}$ (fold change) (" $\log _{2}$ (competition)") of peptides isolated from cells treated with $\mathbf{1}$ or $\mathbf{1}+20(S)$-OHC. Cutoffs discussed in the text at a pvalue of 0.05 and a fold change of 2 are indicated.

e. Scatter plot of enrichment versus competition for $\mathbf{1}$ target proteins. Proteins selected for Western blot analysis are shown as bubbles, where size and color of represent p-values for competition and enrichment, respectively.

f. Western blot analysis of proteins labeled by 1 in the presence or absence of 20(S)-OHC or DMSO alone, clicked to biotin, enriched on streptavidin, and resolved by SDS-PAGE.

\section{Fig. 5: Tmem97 is a selective protein target of probe 1.}

a. Left: A fluorescent band at $21 \mathrm{kDa}$ in the membrane proteome of 1-labeled cells is eliminated by competition with BIMU-8, a Tmem97 ( $\sigma 2$ receptor) ligand, but not PRE-084, a $\sigma 1$ receptor ligand. Middle: Competition with BIMU-8, but not PRE-084, reduces biotin labeling and Tmem97 antibody detection of the band at $21 \mathrm{kDa}$. Right: structures of PRE-084 and BIMU-8.

b. Biotin labeling and Western blot detection of Tmem97 show that the probe-labeled band at $21 \mathrm{kDa}$ is reduced by $20(S)$-OHC in a dose-dependent manner.

c. The intensity of the probe-labeled $21 \mathrm{kDa}$ band is dramatically reduced in Tmem97 knockout cells. TAMRA fuorescence (top) and Tmem97 antibody signal (bottom) from wild type and Tmem97-KO NIH-3T3 cells treated with 1 (duplicate samples) or DMSO.

d. In-gel analysis of competition experiments with 20(S)-OHC, 25-OHC, inositol, palmitoylethanolamine (PEA), cholesterol, and 20(R)-OHC show reduction of the probe-labeled 21 $\mathrm{kDa}$ band at various levels, suggesting structure-selective binding to Tmem97.

e. Homology model of mouse Tmem97 based on the cryo-EM structure of human Ebp (PDB 6OHT). 20(S)-OHC docks in a central binding pocket, indicated by a black circle.

f. Alanine substitution of the Y150 residue in the predicted Tmem97:20(S)-OHC binding site eliminates labeling of overexpressed Tmem97 protein in HEK293T cells. E61A and W95A mutants remain susceptible to labeling by $\mathbf{1}$, while an F88A mutant fails to express in cells. 


\section{Figures}

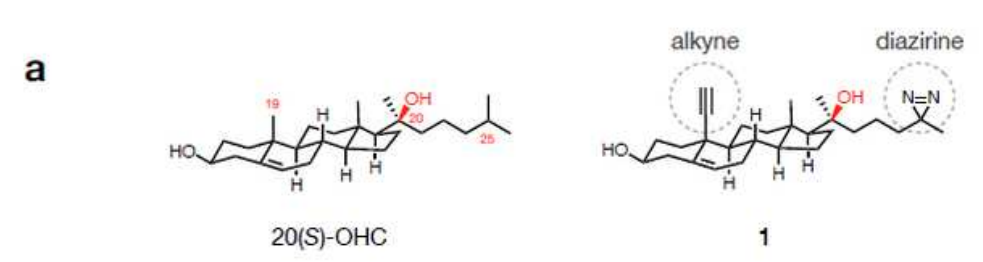

\section{b}
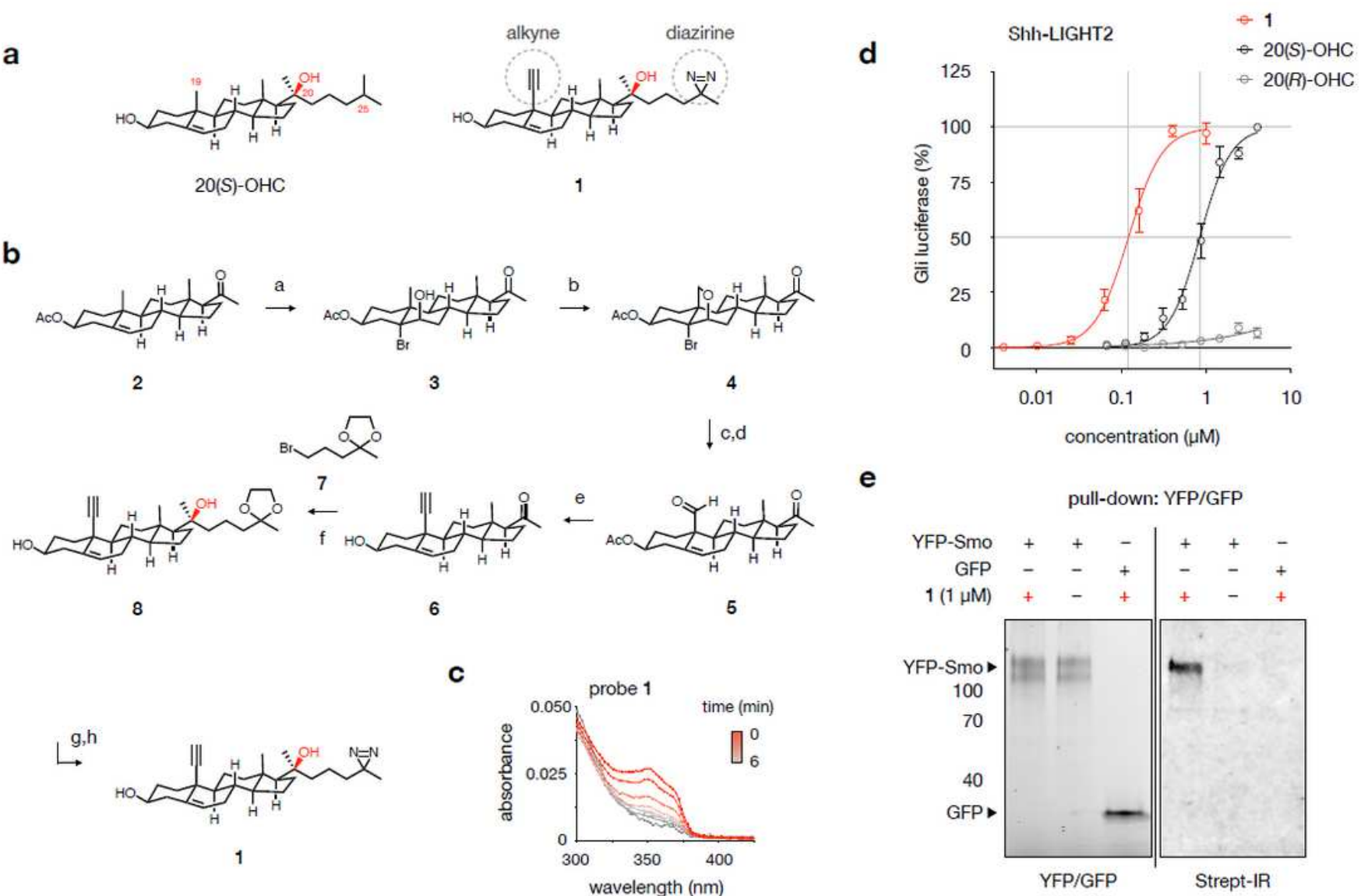

\section{Figure 1}

Design, synthesis, and evaluation of 20(S)-OHC chemoproteomics probe 1. a. Structures of 20(S)hydroxycholesterol (20(S)-OHC) and the photoactivable, clickable analogue 1, which contains a diazirine at C25 for photocrosslinking and an alkyne at C19 for click chemistry. b. Chemical synthesis of probe 1. Conditions: a. NBA, aq. HClO4, 1,4-dioxane, $0 \otimes 23{ }^{\circ} \mathrm{C}, 77 \%$; b. $\mathrm{Pb}(\mathrm{OAc}) 4, \mathrm{CaCO} 3$, I2, hv, cyclohexane, $80{ }^{\circ} \mathrm{C}$, > 99\%; c. Zn, AcOH-H2O, $45^{\circ} \mathrm{C}, 88 \%$; d. PCC, Celite, $\mathrm{CH} 2 \mathrm{Cl} 2,23{ }^{\circ} \mathrm{C}, 87 \%$; e. (i) Seyferth-Gilbert reagent, tBuOK, THF, $-78{ }^{\circ} \mathrm{C}, 80 \%$; (ii) Cs2CO3, $\mathrm{MeOH}, 23{ }^{\circ} \mathrm{C}$, >99\%; f. 2-(3-bromopropyl)-2-methyl-1,3-dioxolane, Mg, THF, $0 \otimes 23{ }^{\circ} \mathrm{C}, 66 \%$; g. $\mathrm{HCl}, \mathrm{THF}, 23{ }^{\circ} \mathrm{C}, 94 \%$; h. (i) $\mathrm{NH} 3, \mathrm{MeOH}, 0{ }^{\circ} \mathrm{C}$; (ii) $\mathrm{NH} 2 \mathrm{HSO} 3,0 \otimes 23{ }^{\circ} \mathrm{C}$; (iii) I2, Et3N, THF, $23{ }^{\circ} \mathrm{C}, 46 \%$. c. Irradiation of probe 1 (10 mM, DMF) with $368 \mathrm{~nm}$ light results in loss of diazirine absorption at $353 \mathrm{~nm}$ with a half-life of 1.4 minutes. Values are the average of triplicate measurements \pm s.d. d. Treatment of Shh-LIGHT2 cells with 20(S)-OHC, 20(R)-OHC, or probe 1 demonstrates that 20(S)$\mathrm{OHC}$ and 1, but not the inactive epimer 20(R)-OHC, activate the Smoothened-regulated Gli transcription factors. Values are the average of 3 biological replicates \pm s.d. e. Left: In-gel fluorescence analysis of membrane fractions from HEK293T cells overexpressing YFP-Smo or GFP. Live cells were treated with 1 or DMSO and irradiated, then YFP-Smo or GFP were isolated from membrane fractions using a GFP nanobody that binds both fluorescent proteins. Isolated proteins were subjected to a click reaction to 
biotinylate crosslinked proteins. Right: Detection of biotinylated proteins using Streptavidin IRDye 800CW (Strept-IR) demonstrates that 1-treated YFP-Smo-expressing cells are labeled with biotin. YFP-Smoexpressing cells treated with DMSO and GFP-expressing cells treated with 1 show no biotin labeling.

a

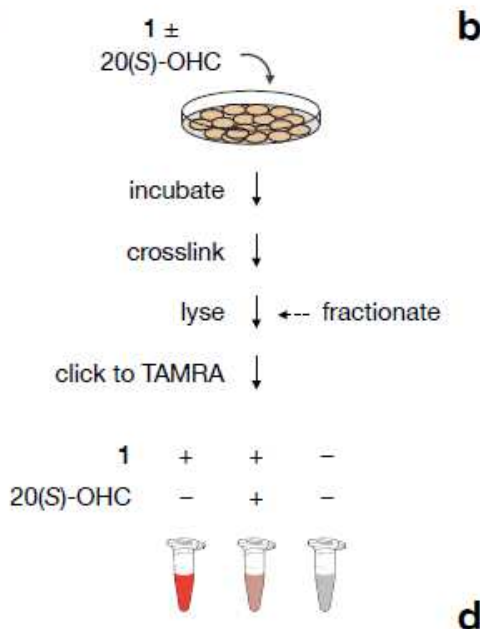

SDS-PAGE $\downarrow$

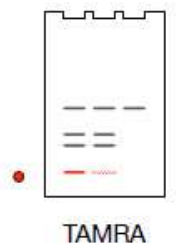

b

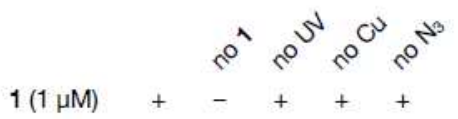

d

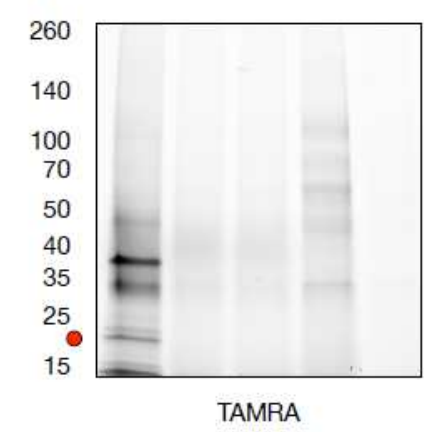

$\begin{array}{llllll}1(\mu M) & 20 & 10 & 5 & 1 & 0\end{array}$

40

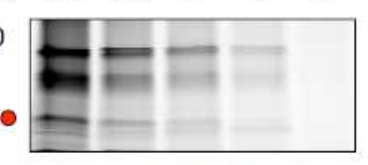

TAMRA
C
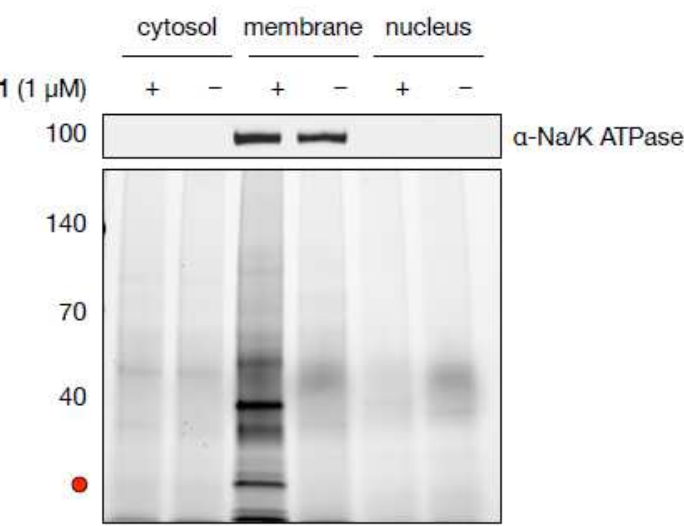

TAMRA

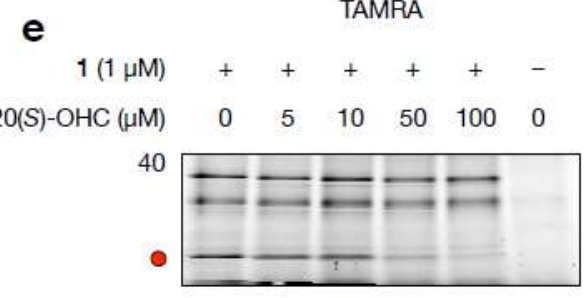

TAMRA

Figure 2

Probe 1 labels membrane proteins in live NIH-3T3 cells. a. Workflow for gel-based profiling of probe 1 target proteins. Cells are incubated for 30 min with $1 \mu \mathrm{M}$ 1, DMSO, or $1 \mu \mathrm{M} 1+50 \mu \mathrm{M} 20$ (S)-OHC and irradiated for $5 \mathrm{~min}$ with $368 \mathrm{~nm}$ light. Isolated membrane fractions are subjected to a click reaction with TAMRA azide, separated by SDS-PAGE, and identified by in-gel fluorescence. b. Control experiments demonstrate that fluorescent labeling requires treatment with 1, exposure to UV light, and click ligation to TAMRA. In "no 1", cells were incubated with DMSO only; in "no UV"; probe-treated cells were not exposed to $368 \mathrm{~nm}$ light; in "no Cu", CuSO4 was omitted from the click reaction; in "no N3", TAMRA azide was omitted from the click reaction. c. Cell fractionation shows that TAMRA-labeled proteins appear primarily in the membrane fraction, as opposed to cytosolic or nuclear fractions. The Sodium/potassiumtransporting ATPase subunit alpha- 1 (Na/K ATPase) was used as a membrane marker. $\mathrm{d}$. Proteins in the membrane fraction are labeled by 1 in a dose-dependent manner. e. Competition by 20(S)-OHC during incubation of cells with 1 reduces TAMRA labeling of a $21 \mathrm{kDa}$ band in a dose-dependent manner. 
a

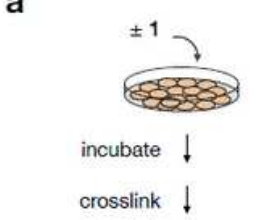

lyse; fractionate ।

click to biotin !

enrich with

streptavidin

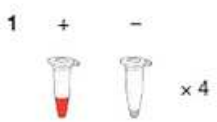

digest

isotope tag $\downarrow \therefore 0 \% \pm$

combine ।

RTS-SPS-MS ${ }^{3}$ !

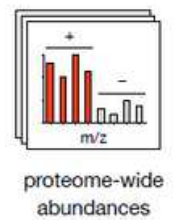

b

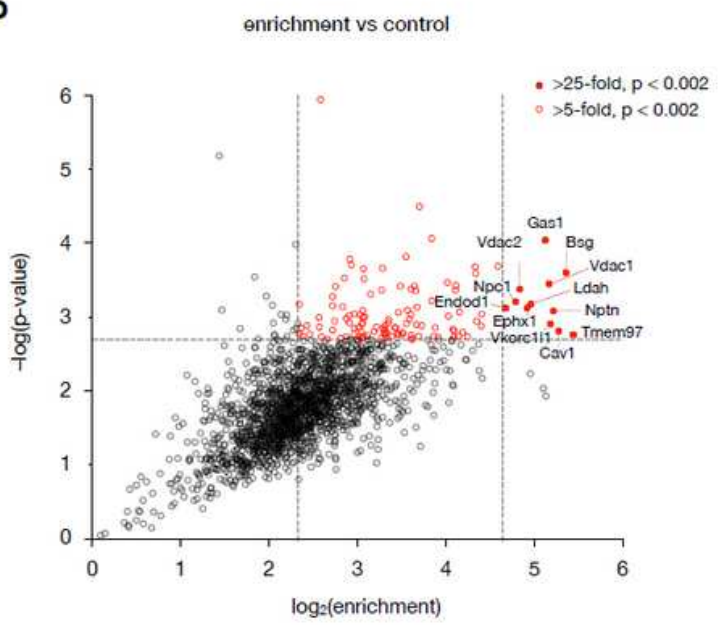

d

immunologic signature

IL6_IL1_VS_IL6_HL1_IL23_TREATED_CD4_TCELL_DN, FDR $=0.009$

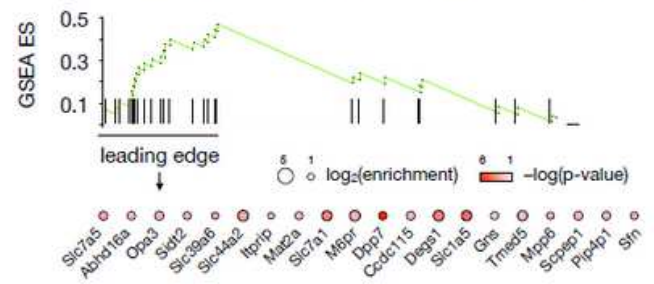

c

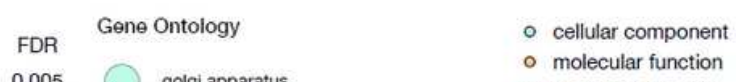

0 molecular function

$0.004 \bigcirc$ molecular transducer activity biological process

$0.005 \bigcirc$ intrinsic component of plasma membrane

$0.004 \bigcirc$ golgi membrane

$0.005 \bigcirc$ nuclear outer membrane ER membrane network

$0.007 \quad$ exocytic vesicle

0.011

0.014

0.033

0.039

0.044

0.044

0.068

0.075

0.087

trans golgi network

long term synaptic potentiation

membrane lipid metabolic processes

transporter activity

SNAP receptor activity

sphingolipid metabolic processes

response to ionizing radiation

ion transmembrane transporter activity

- secondary active transmembrane transporter activity

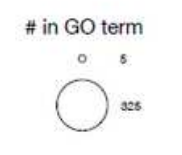

e

oncogenic signature

TBK1.DF_UP, FDR $=0.071$

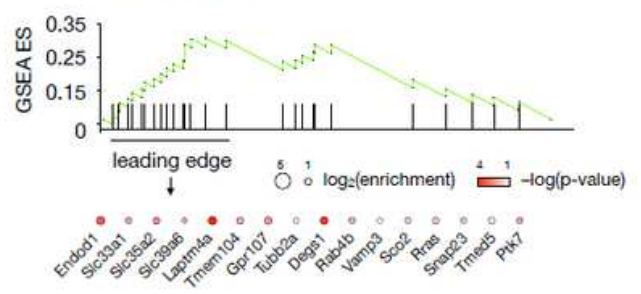

\section{Figure 3}

Protein targets of probe 1 converge in distinct gene ontologies and disease signatures. a. Workflow for MS-based profiling of probe 1 target proteins. Cells are incubated for 30 min with $1 \mu \mathrm{M} 1$ or DMSO and irradiated for $5 \mathrm{~min}$ with $368 \mathrm{~nm}$ light. Isolated membrane fractions are subjected to a click reaction with biotin picolyl azide, enriched with streptavidin agarose, and digested with trypsin. Digested peptides from each sample are labeled with unique isobaric mass tags, then samples are pooled and analyzed by LC/RTS-SPS-MS3. Data represent of 4 biological replicates of matched experiments with 1 and DMSO. b. Volcano plot showing statistical significance versus average log2(fold change) ("log2(enrichment)") of peptides isolated from cells treated with 1 or DMSO alone. Cutoffs discussed in the text at a p-value of 0.002 and fold changes of 25 and 10 are indicated. See also Fig S1, Fig S2A,B,C, and File S1. c. Gene Set Enrichment Analysis (GSEA) of 1-enriched proteins using Gene Ontology (GO) gene set. The top 16 GO pathways ranked by NES (Normalized Enriched Score) are listed. Bubbles are colored according to GO term class; bubble size is proportional to the number of 1-enriched proteins found in each gene set. (d),(e) GSEA using the immunologic (D) and oncogenic (E) signature gene sets for 1-enriched proteins. Enriched proteins the leading edge of the gene set are listed below; color and size of the bubbles represent $\log 2$ (enrichment) and -log(p-value), respectively. 


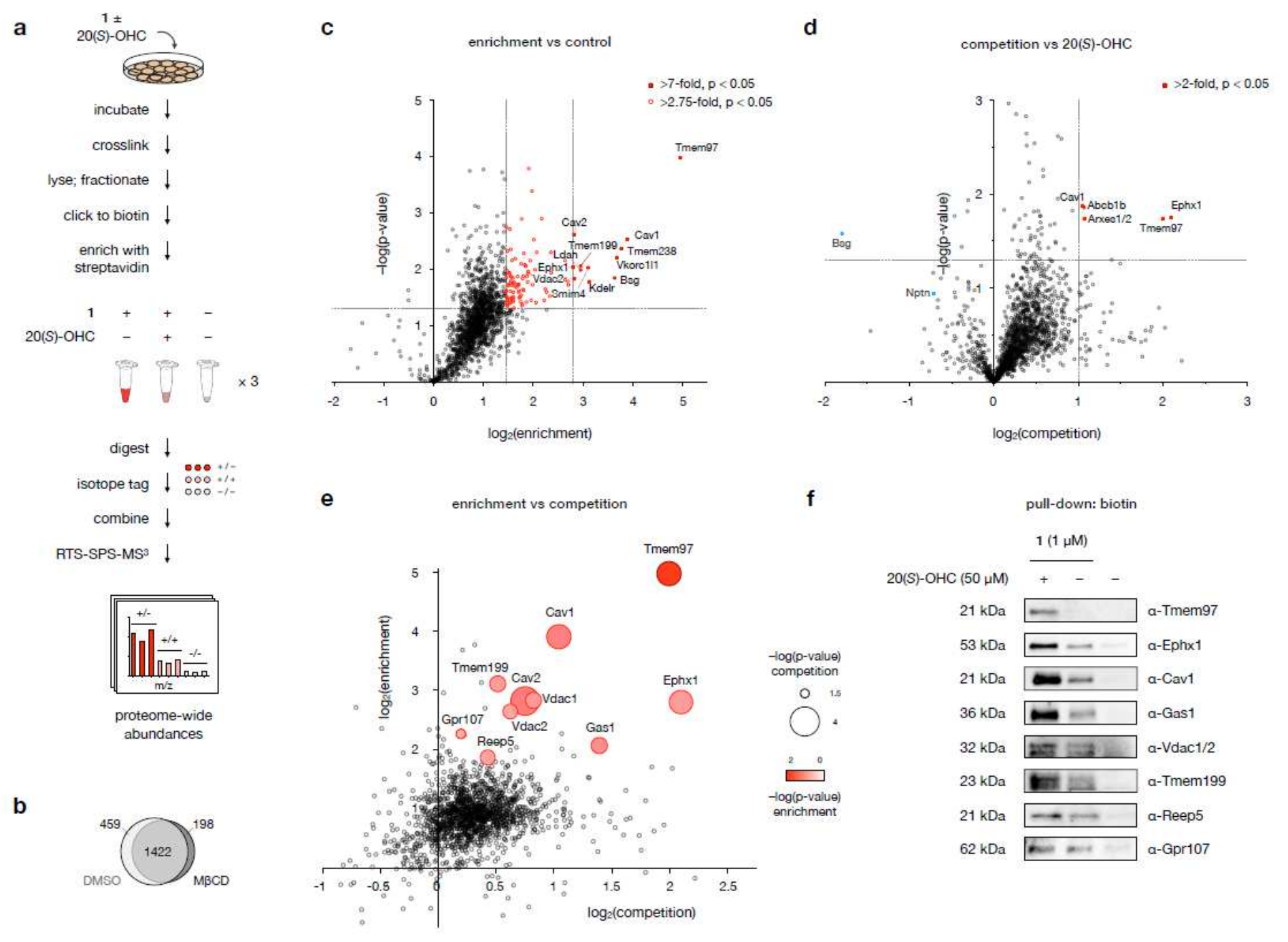

Figure 4

20(S)-OHC identifies enriched and competable probe 1 target proteins. a. Workflow for MS-based profiling of probe 1 target proteins. Cells are preincubated with $50 \mu \mathrm{M} 20(\mathrm{~S})-\mathrm{OHC}$ complexed with M $\beta C D$ or M $\beta C D$ alone for $1 \mathrm{~h}$ before addition of $1 \mu \mathrm{M}$ probe 1 or DMSO and incubation for $30 \mathrm{~min}$. Cells are irradiated for 5 min with $368 \mathrm{~nm}$ light, then isolated membrane fractions are subjected to a click reaction with biotin picolyl azide, enriched with streptavidin agarose, and digested with trypsin. Digested peptides from each sample are labeled with unique isobaric mass tags, then samples are pooled and analyzed by LC/RTSSPS-MS3. Data represent 3 biological replicates of matched experiments with 1,1+20(S)-OHC, and DMSO. $b$. Venn diagram of proteins enriched by probe 1 in the presence and absence of M $\beta C D$. See also Fig. S3a,b,c. c. Volcano plot showing statistical significance versus average log2(fold change) ("log2(enrichment)") of peptides isolated from cells treated with $1 \mu \mathrm{M} 1$ or DMSO alone. Cutoffs discussed in the text at a p-value of 0.05 and fold changes of 7 and 2.5 are indicated. See also File S1. d. Volcano plot showing statistical significance versus average log2(fold change) ("log2(competition)") of peptides isolated from cells treated with 1 or $1+20$ (S)-OHC. Cutoffs discussed in the text at a p-value of 0.05 and a fold change of 2 are indicated. e. Scatter plot of enrichment versus competition for 1 target proteins. Proteins selected for Western blot analysis are shown as bubbles, where size and color of 
represent $p$-values for competition and enrichment, respectively. $\mathrm{f}$. Western blot analysis of proteins labeled by 1 in the presence or absence of $20($ S)-OHC or DMSO alone, clicked to biotin, enriched on streptavidin, and resolved by SDS-PAGE.

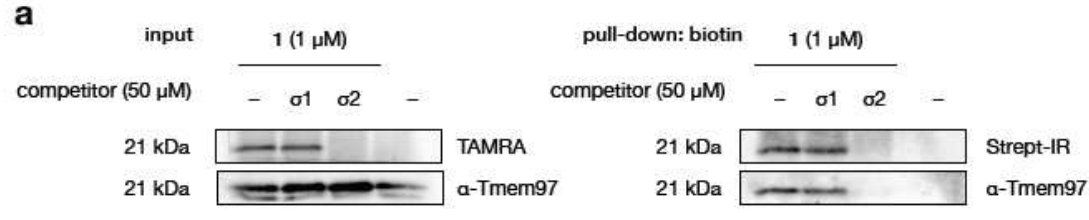

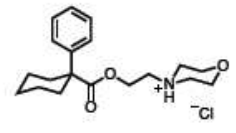

PRE-084 ( 61 ligand)

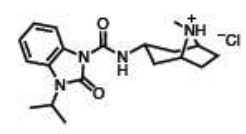

BIMU-8 ( 62 ligand)

b
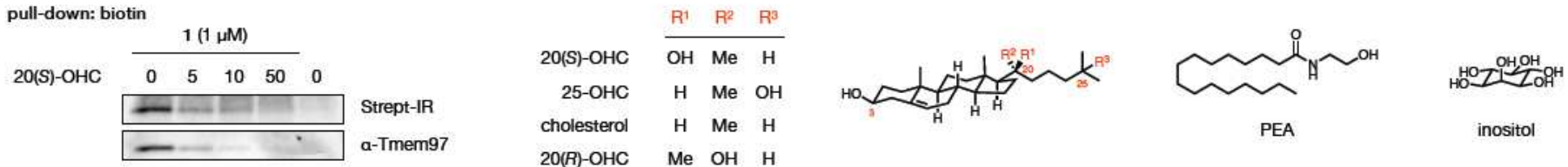

20(R)-OHC $\mathrm{Me} \mathrm{OH} \mathrm{H}$

C

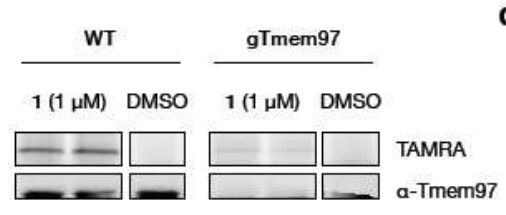

e

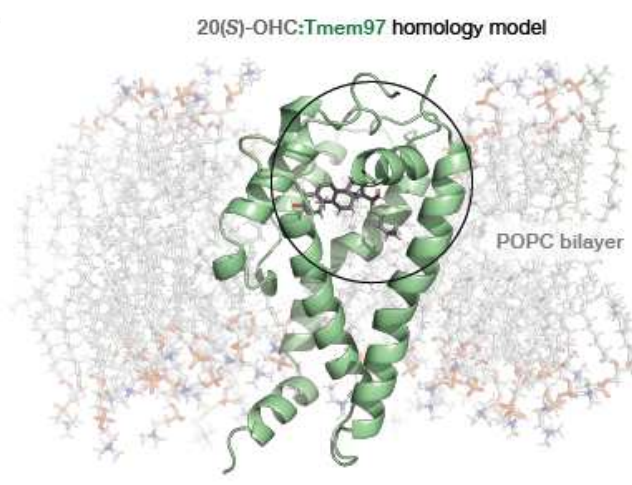

d

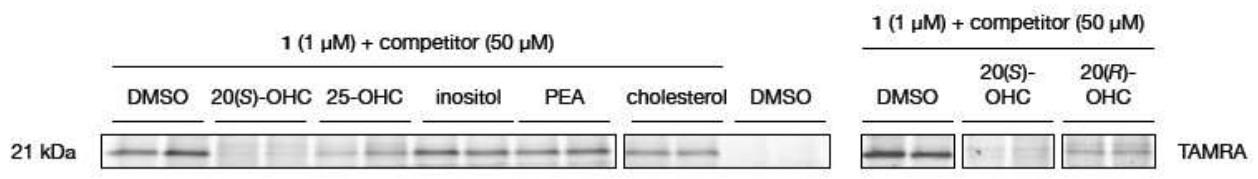

\section{Figure 5}
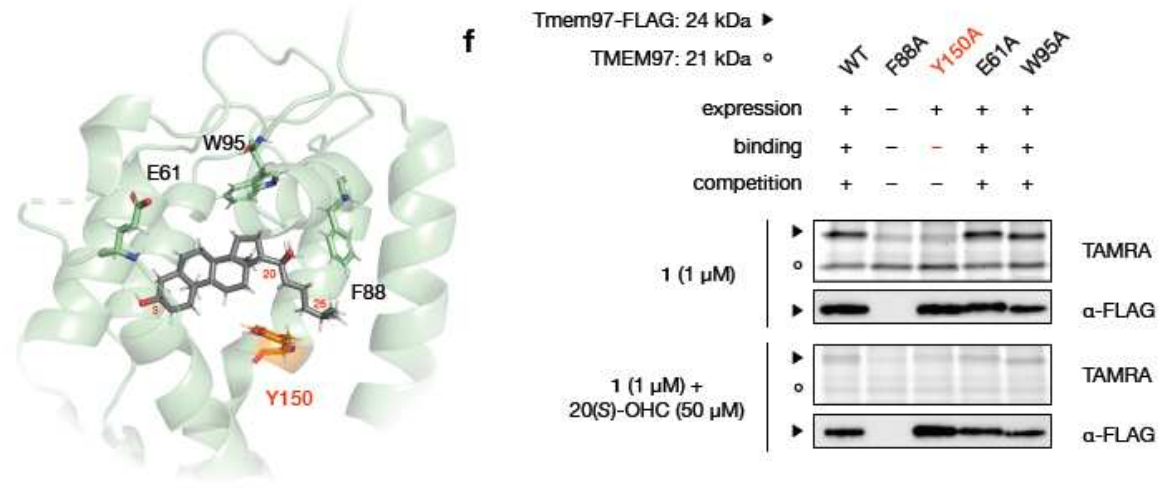

Tmem97 is a selective protein target of probe 1. a. Left: A fluorescent band at $21 \mathrm{kDa}$ in the membrane proteome of 1 -labeled cells is eliminated by competition with BIMU-8, a Tmem 97 ( $\sigma 2$ receptor) ligand, but not PRE-084, a $\sigma 1$ receptor ligand. Middle: Competition with BIMU-8, but not PRE-084, reduces biotin labeling and Tmem97 antibody detection of the band at $21 \mathrm{kDa}$. Right: structures of PRE-084 and BIMU-8. b. Biotin labeling and Western blot detection of Tmem 97 show that the probe-labeled band at $21 \mathrm{kDa}$ is reduced by 20 (S)-OHC in a dose-dependent manner. c. The intensity of the probe-labeled $21 \mathrm{kDa}$ band is dramatically reduced in Tmem97 knockout cells. TAMRA fuorescence (top) and Tmem97 antibody signal (bottom) from wild type and Tmem97-KO NIH-3T3 cells treated with 1 (duplicate samples) or DMSO. d. Ingel analysis of competition experiments with 20 (S)-OHC, 25-OHC, inositol, palmitoylethanolamine (PEA), cholesterol, and 20(R)-OHC show reduction of the probe-labeled $21 \mathrm{kDa}$ band at various levels, suggesting structure-selective binding to Tmem97. e. Homology model of mouse Tmem97 based on the cryo-EM structure of human Ebp (PDB 6OHT). 20(S)-OHC docks in a central binding pocket, indicated by a black circle. $\mathrm{f}$. Alanine substitution of the $\mathrm{Y} 150$ residue in the predicted Tmem97:20(S)-OHC binding site 
eliminates labeling of overexpressed Tmem97 protein in HEK293T cells. E61A and W95A mutants remain susceptible to labeling by 1 , while an F88A mutant fails to express in cells.

\section{Supplementary Files}

This is a list of supplementary files associated with this preprint. Click to download.

- Dataset1.xlsx

- 20210219ChengSI.pdf 